Check for updates

Cite this: Mater. Chem. Front., 2020, 4, 2235

Received 3rd May 2020, Accepted 3rd June 2020

DOI: $10.1039 / \mathrm{d} 0 \mathrm{qm} 00296 \mathrm{~h}$

rsc.li/frontiers-materials

\section{Ring-opening Metathesis Polymerisation derived poly(dicyclopentadiene) based materials}

\author{
Sebastijan Kovačič (iD) a and Christian Slugove (D) *bc
}

\begin{abstract}
During the last two decades, poly(dicyclopentadiene) prepared by Ring-opening Metathesis Polymerisation has emerged as an important competitor for epoxy- and polyester resins. This review article summarises the contributions from academia in this timeframe. The fields of initiator system development, polymer chemistry and physics, composites of poly(dicyclopentadiene), use in self-healing composites, novel processing opportunities and macro- as well as microporous materials are covered.
\end{abstract}

\section{Introduction}

Dicyclopentadiene (DCPD) ${ }^{1}$ is obtained as a by-product from steam cracking performed during the production of ethylene., DCPD finds applications in unsaturated polyester and hydrocarbon resins, in ethylene propylene diene monomer (EPDM) elastomers, as chemical feedstock, in cyclic olefin polymers and as a monomer for poly(dicyclopentadiene) (pDCPD) prepared

\footnotetext{
${ }^{a}$ National Institute of Chemistry, Department of Polymer Chemistry and Technology, Hajdrihova 19, 1000 Ljubljana, Slovenia

${ }^{b}$ Institute for Chemistry and Technology of Materials, Graz University of Technology, Stremayrgasse 9, A 8010 Graz, Austria. E-mail: slugovc@tugraz Christian Doppler Laboratory for Organocatalysis in Polymerization, Stremayrgasse 9, A 8010 Graz, Austria
}

via Ring-opening Metathesis Polymerisation (ROMP). The worldwide DCPD market is estimated to exceed 500 million Euro in 2019 and is expected to grow by annually 5\% over the next 5 years. ${ }^{4}$ Especially the market segment of highly purified DCPD is gaining growth rate as pDCPD increasingly finds applications. ROMP of DCPD results in a cross-linked polymer that possesses high notch-impact strength and offers high temperature and corrosion resistant properties as well as high stability versus chemicals. Furthermore, the polymer's surface is quickly oxidized in air and thus a relatively polar surface is generated which can be easily painted. An additional corona treatment or flaming as required for many other polymers is thus not necessary. ROMP-derived pDCPD is used for example in the manufacturing of agricultural equipment, of body panels, and of cells for the chlor-alkali industry or in the

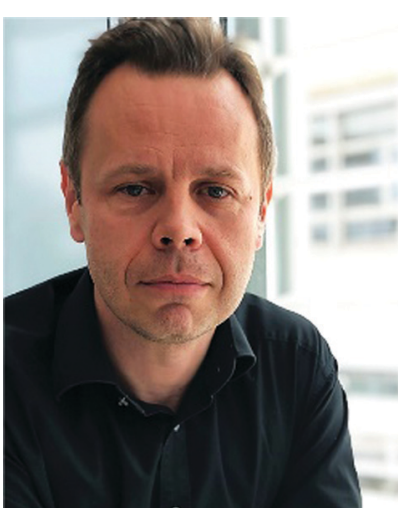

Sebastijan Kovačič
Sebastijan Kovačič received his $\mathrm{PhD}$ in Chemistry from the University of Maribor, Slovenia, in 2011 working on hybrid polyHIPE materials. After a twoyears postdoctoral stay at the Graz University of Technology with Prof. C. Slugovc, he received an Aly Kaufman Fellowship of Trust and joined the group of Prof. $M . S$. Silverstein at Technion, Israel Institute of Technology. Since 2014, he has been a research associate at the National Institute of Chemistry (NIC), Slovenia. His main research interests focus on emulsions, their generation and stability, and the various porous materials that can be synthesized therefrom including nanocomposites, hydrogels or carbons.

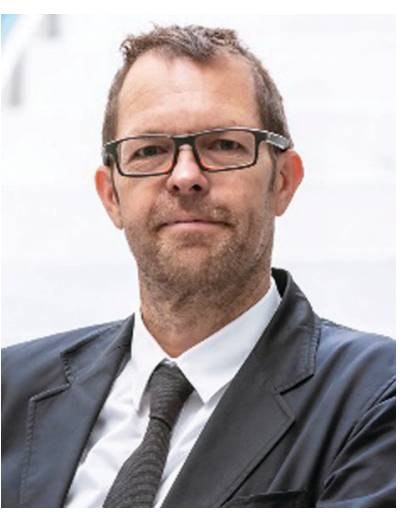

Christian Slugove
Christian Slugovc received his PhD from Vienna University of Technology in 1998 under the supervision of Prof. K. Kirchner. From 1999 to 2000 he did a postdoctoral stay at the CSICSevilla with Prof. E. Carmona. Afterwards he joined Graz University of Technology and habilitated in macromolecular chemistry in 2007. Currently he is an associate professor, deputyhead of Graz University of Technology's lead-project Porous Materials@Work and the director of the Christian Doppler Laboratory for Organocatalysis in Polymerisation. His current research strives towards advancing the efficacy in synthetic macromolecular chemistry and bringing (organic) materials to work. 
petrochemical industry for piping. Furthermore, reinforced pDCPD parts became accessible and enabled new concepts for construction designs. pDCPD is mainly processed via reaction injection moulding (RIM), resin transfer moulding (RTM) and vacuum-assisted RTM (VTRTM). ${ }^{5-10}$ By these techniques large and complex parts can be manufactured in a quick and efficient way. Its comparatively low density combined with good mechanical properties makes it environmentally beneficial for applications in the automotive domain, where fuel efficacy is an important topic. Lately pDCPD based technology has additionally targeted, amongst others, the markets of downhole tools, subsea insulation, circuit boards, pressure vessels and parts for the energy generating industry.

Herein the research on pDCPD-based materials conducted in roughly the last two decades in academia is summarized. Emphasis is laid on ruthenium based initiating systems.

\section{Contemporary research directions}

\subsection{Processing of DCPD - the need for latent initiators}

The initially implemented RIM processing of DCPD is based on mixing two monomer streams, one containing a pre-initiator and the second an activator, just before the combined resin is injected into the mould. Additionally, a retarder is added to adjust the (usually short) induction period, facilitating the filling of the mould. ${ }^{11}$ This implementation is by far not ideal when more time to fill the mould (big parts, parts exhibiting shapes with different aspect ratios, and fabrication of reinforced parts) is needed. Furthermore, classical initiation systems are sensitive to moisture and air, limiting also the use of many co-monomers and/or fillers.

Therefore, a lot of attention has been devoted to the development of latent and insensitive initiation systems. ${ }^{12}$ Of particular interest is to enable so-called one-component systems. In such resins, the monomers and the initiator are already combined and polymerisation is then started after a predetermined time or by an external stimulus, in most cases elevated temperature. Such one-component resins facilitate RTM and VTRTM but also RIM processes in terms of providing long working time and better chemical compatibility with other ingredients as well as oxygen and moisture. Additionally, less sophisticated process machineries can be employed. Amongst thermally switchable initiators, also initiators which can be triggered by light, acids, redoxreactions and mechanical force have been investigated. ${ }^{12-15}$ Most initiator systems are based on ruthenium because of its high functional group tolerance and insensitivity towards oxygen and protic groups.

2.1.1. Thermally switchable initiators. There are three principal ways to design (well-defined ruthenium based) thermally switchchable initiators (Scheme 1). Type 1 systems rely on strong Ru- ${ }^{1}$ bonds (Type 1, B). In simplified words, the ligand

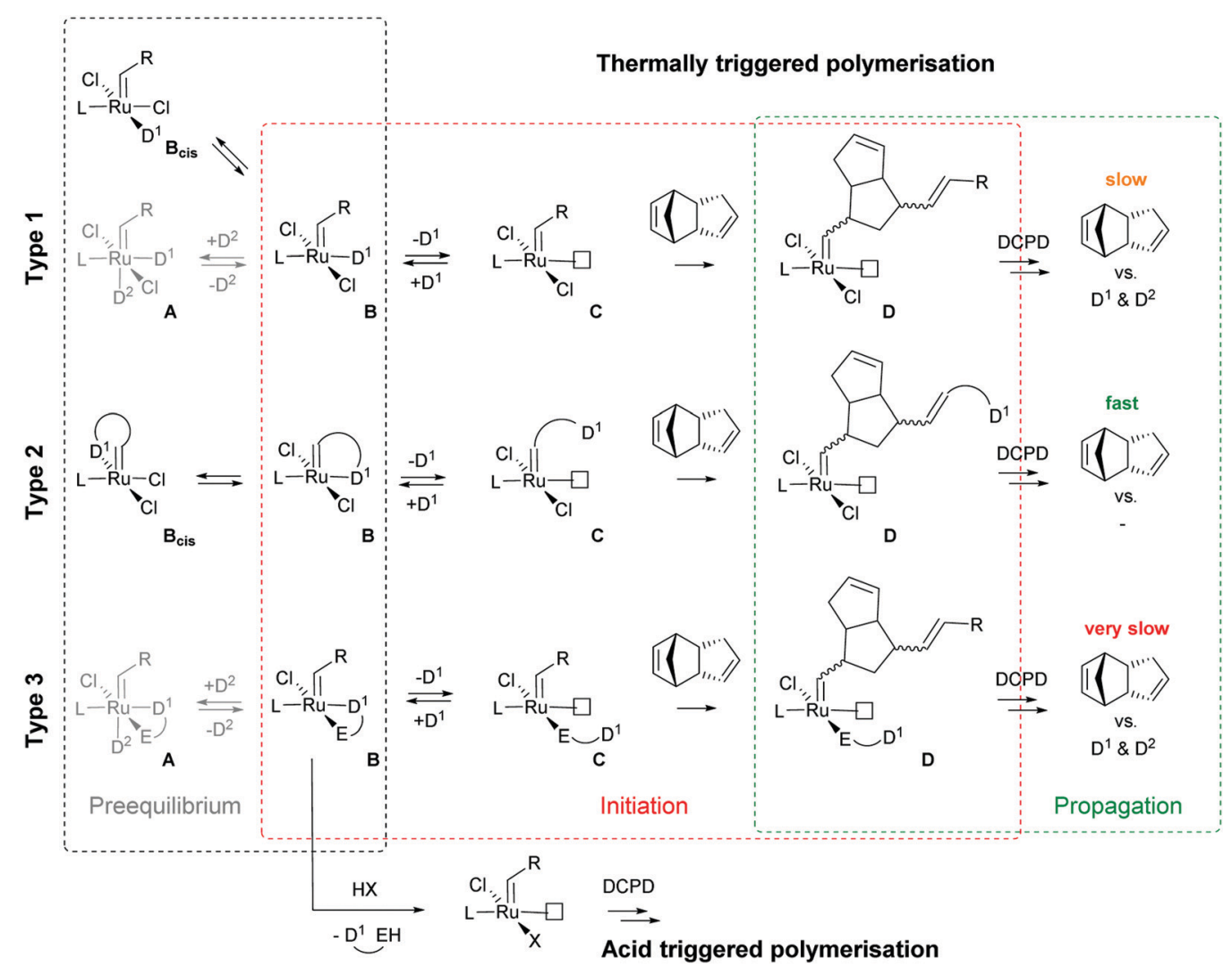

Scheme 1 Most common avenues towards latent Ru-based initiators. L is typically a phosphine or an N-heterocyclic olefin; $D^{1}$ and $D^{2}$ are typically $\sigma$ - or $\pi$-donor ligands such as amines, phosphines or $\mathrm{N}$-heterocyclic carbenes; $\mathrm{E}$ is typically $\mathrm{O}$ or $\mathrm{S}$; and $\mathrm{R}$ is typically an organic rest like a phenyl group. 

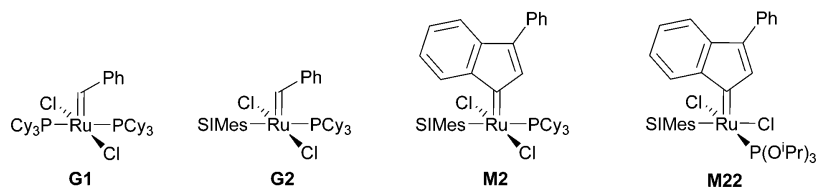

Fig. 1 Commercial Type 1 initiators used for the polymerisation of DCPD. $\mathrm{PCy}_{3}=$ tricyclohexylphosphine; SIMes = 1,3-dimesitylimidazolidin-2-ylidene

$\mathrm{D}^{1}$ has to leave the coordination sphere in order to provide an empty coordination site (Type $1, \mathbf{C}$ ) for the proper coordination of the monomer. ${ }^{16}$

Subsequently the metathesis event takes place providing the initiation (Type 1, D). During propagation, the decoordinated ligand $\mathrm{D}^{1}$ is competing with DCPD for the vacant coordination site. Therefore, propagation is relatively slow. Upon adding more donor ligand $\left(\mathrm{D}^{2} ; \mathrm{D}^{2}\right.$ could be the same as $\left.\mathrm{D}^{1}\right)$, both initiation and propagation are further decelerated. ${ }^{17,18}$ In most publications the commercially available initiators $\mathbf{G} 1^{19,20}$ or $\mathbf{G} 2^{21,22}$ are used (Fig. 1) and, if necessary, the working time is adjusted upon addition of additional donor ligands like with amines, ${ }^{18}$ phosphines, ${ }^{23-25}$ N-heterocyclic carbenes ${ }^{26,27}$ or phosphite esters. ${ }^{28}$ Additionally, $\mathbf{M} 2$, an analogue of G2, is commercially available and exhibits a better latent behaviour than e.g. G2. ${ }^{29}$ Another way to create initiators that are distinctly more latent is to employ Type 1 preinitiators exhibiting a cis-dichloro stereochemistry $\left(\mathbf{B}_{\text {cis }}\right)$. However, only a few cis-dichloro configured initiators of Type 1 are known. ${ }^{30}$ In this case, the metathetically inactive $\mathbf{B}_{\text {cis }}$ has to isomerize to the corresponding trans-dichloro form before initiation can start. As the only representative of this family, initiator $\mathbf{M 2 2}$ was benchmarked against G2 and M2 and showed by far the highest latency. ${ }^{29}$ Note that $10-30 \mathrm{ppm}$ initiator (G2, M2 or M22) is sufficient to obtain pDCPD parts with similar mechanical characteristics to industrially manufactured samples.

In a second layout, the Type 2 system, a chelating carbene ligand is used (B). In that case, the decoordination of $\mathrm{D}^{1}$ is entropically disfavoured and, accordingly, initiation is slowed down. The effect becomes even bigger if the corresponding cis-dichloro isomer $\left(\mathbf{B}_{\text {cis }}\right)$ is used. Once initiated (Type 2, D), the chelate effect is cancelled because $\mathrm{D}^{1}$ is moved away from the metal centre and propagation is relatively fast. Note that addition of donor ligands (used to increase the processing window in Type 1 initiators) could have counterproductive effects because dechelation is accelerated in this case. ${ }^{31}$ As in the case of Type 1 initiators many potential latent compounds have been disclosed, ${ }^{32}$ but only a few have been described according to their performance in polymerising DCPD. ${ }^{33-38}$ Fig. 2 shows exemplary Type 2 initiators which were tested. Most of them feature a nitrogen as the second ligand atom of the chelate ring (1-3),
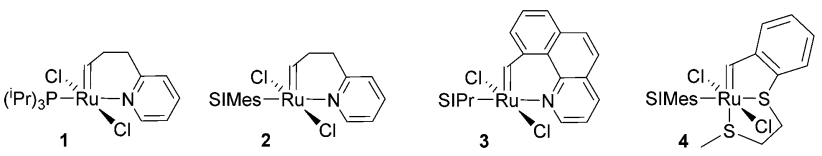

Fig. 2 Selected examples of Type 2 initiators tested in the polymerisation of DCPD. but also the sulphur-based variant 4 has been described. ${ }^{39}$ Although the different testing conditions used in the literature do not allow for identifying the best candidates, it is revealed that often subtle changes of the initiator structures cause big differences in their latency. Perhaps this is the reason why such Type 2 initiators are rarely applied in preparing PDCPD in the open research literature, although some of them are even commercialized. ${ }^{40-42}$

In a third layout, the donor ligand is tethered to an anionic ligand (Type 3, B). ${ }^{43,44}$ Variants featuring two such chelating ligands are also known. ${ }^{4,46}$ Similarly to Type 2 initiators, the chelate effect slows down the initiation, but also propagation is distinctly decelerated. Therefore, this layout is rather used in acid switchable systems (vide infra). Finally, a combination of Type 2 and 3, i.e. chelation takes place via the alkylidene and an anionic ligand, is known. ${ }^{47-49}$

In the area of potentially less toxic molybdenum and tungsten imido alkylidene complexes, the first latent and considerably air and moisture tolerant initiators for DCPD have been described recently. ${ }^{50,51}$ For more sensitive initiators a protection strategy by encapsulation in paraffin is available. ${ }^{52}$

As already emphasised, a meaningful comparison of the performance of the different initiators is hard to make. A standardized test protocol, as available for other olefin metathesis reactions, is missing. ${ }^{53}$ As a first step to establish such a protocol, it is suggested to study the curing of DCPD at low initiator loadings (e.g. $30 \mathrm{ppm}$ with respect to DCPD) using thermogravimetric analysis coupled with differential scanning calorimetry (e.g. with a heating ramp of $\left.3{ }^{\circ} \mathrm{C}\right) .{ }^{29}$ Additionally the quest towards latent initiators which are soluble in the monomer is underdeveloped. Solvents are undesirable in many processing technologies for DCPD and the solubility of many initiators in DCPD is limited.

2.1.2. Acid switchable initiators. Initiators that are inactive at ambient temperature but can be activated upon addition of another chemical resemble the classical way of processing DCPD in RIM. However, in the case where ruthenium preinitiators are used, the advantage of a higher functional group tolerance compared to the classical initiator systems is gained. In ruthenium chemistry, the activator for the pre-initiator is an acid, which is able to remove (at least one donor of) the chelating ligand from the central atom (Scheme 1) and is able to provide the anionic ligand, necessary to guarantee the ROMP-activity of the initiator. Amongst processing DCPD via the classical methods, also a switchable polymerisation of emulsions by this approach has been described. ${ }^{54}$

2.1.3. Light switchable initiators. In applications like coatings or additive manufacturing light curing resins are desirable. Not surprisingly, research on light triggered olefin metathesis reactions has been conducted over the years. ${ }^{55}$ Nevertheless, research on light curing resins based on ROMP-able monomers in general and on DCPD based resins in particular is scarce. Early work used ill-defined ruthenium-arene complexes and solvated $\mathrm{Ru}(\mathrm{II})$ species. ${ }^{56,57}$ This concept was further elaborated leading to several pre-initiators which can be activated with UV-light of $254 \mathrm{~nm}$ (and $308 \mathrm{~nm}$ ) being the key-component for 
DCPD based negative resists. ${ }^{58,59}$ A similar concept uses the photogeneration of an N-heterocyclic carbene which subsequently creates an ill-defined initiator. ${ }^{60,61}$ Also Type 1 (e.g. M22) and Type 2 thermally latent initiators can by activated by light and polymerize DCPD. ${ }^{62,63}$ Recently, a phosphite ester bearing a Type 1 complex with improved absorbance was disclosed. A formulation containing DCPD and 200 ppm of this compound serving as a photoinitiator was used for stereolithography. Layers were successfully cured for 30-60 s with a light source emitting at $385 \mathrm{~nm} .{ }^{64}$ Another recent approach comprises the combination of a Type 1 initiator with a photoredox active pyrylium salt, which allows pDCPD patterning, and photolithography by visible light. $^{65}$ Note that the combination of pyrylium salts and vinylethers allows for the metal free, light triggered polymerisation of DCPD, albeit with only low efficacy and without crosslinking. ${ }^{66}$ Finally, the combination of Type 3 initiators with photoacid generators is used for light curing of cyclic olefins, but DCPD was not tested with such initiator systems. ${ }^{67,68}$

\subsection{Influencing the properties of $\mathrm{pDCPD}$}

2.2.1. Principles and properties. ROMP of DCPD is a chain growth polymerisation process in which the tricyclic monomer is converted into pDCPD via a metal-mediated carbon-carbon double bond exchange process. This implies that the double bonds present in DCPD are still present in the polymer. The polymerisation is driven by the release of strain stored in DCPD and balanced by entropic penalties. ${ }^{69}$ Due to the high ring strain stored in the norbornene part of DCPD, which is approx. $27 \mathrm{~kJ} \mathrm{~mol}^{-1},^{70}$ the polymerisation is highly exothermic. As revealed by several investigations of the cure kinetics of the reaction with mainly $\mathbf{G 1}$ and $\mathbf{G} 2$, a polymerisation enthalpy on the order of 300-450 $\mathrm{J} \mathrm{g}^{-1}$ (depending on different reports) was measured..$^{21,24,71}$ Liquid DCPD has a density of about 0.97 and is converted into pDCPD with a density of roughly 1.03, which constitutes a volumetric shrinkage of $c a$. $6 \%$.

DCPD can exist in two stereoisomers, the endo- and the exo-isomer. Typically commercially available DCPD consists of $>95 \%$ endo-DCPD and most studies and applications use endo-DCPD. However, exo-DCPD polymerises distinctly faster than endo-DCPD. The different polymerisation rates were ascribed to steric effects. In endo-DCPD the penultimate repeating unit is believed to interact with incoming DCPD, thus slowing down the polymerisation. ${ }^{72}$ However, we hypothesise that the higher steric crowding of the more reactive double bond in endo-DCPD (Fig. 3) impedes productive collisions with the metal centre necessary for coordinating the monomer. Proper coordination of the

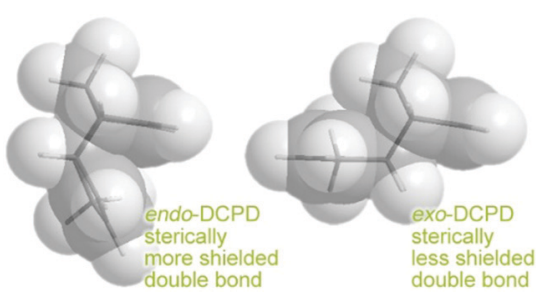

Fig. 3 Space filling cartoons of endo- and exo-DCPD. substrate to the metal alkylidene is known to be the first step in olefin metathesis and should therefore be more facile in the case of exo-DCPD.

Polymerising pDCPD produces in many cases and under most conditions a cross-linked, insoluble material. There has been much debate about the chemical nature of the crosslinks in many studies discussed in this article. Three cross-linking reactions are feasible (especially for initiators like G1 and G2). The most obvious is ring-opening metathesis of the second, less reactive double bond leading to cross-linking of the polymer. $^{73}$ This mechanism operates already at low temperature. The second possibility is olefin addition, which rather takes place at elevated temperatures. ${ }^{74-76,78}$ A third option is oxidative cross-linking, which happens when pDCPD is aging under air (see below). ${ }^{77,78}$ Increased cross-linking is generally reflected in higher glass transition temperatures, ${ }^{79}$ which usually range from 140 to $165{ }^{\circ} \mathrm{C}$ (for cross-linked versions). However, even glass transition temperatures higher than $200{ }^{\circ} \mathrm{C}$ were recorded for pDCPD upon repeated heating-cooling cycles $^{22}$ or prolonged heating. ${ }^{78}$

Cross-linking is a main factor for determining the mechanical properties of the material. Upon changing pDCPD's crosslinking density by copolymerisation of either chain extenders or cross-linkers, the impact of crosslinks on the mechanical properties was investigated. ${ }^{21,80,81}$ Typical mechanical properties of pDCPD comprise a Young's modulus in the range of 1.6-2.0 GPa, tensile stress at yield of about 35-70 MPa and elongation at break from $5-100 \% .{ }^{21,29,71}$ Unlike other thermosetting materials such as epoxy resins, pDCPD lacks strong non-covalent interactions and thus cross-linking is only due to covalent bonds. This is the reason for the pronounced ductility of pDCPD compared to epoxy resins (with a similar glass transition temperature). The ductility results in the high toughness and remarkable impact performance of pDCPD. ${ }^{21}$ The ductility is conserved even at a temperature of $77 \mathrm{~K}^{.82}$ Digging deeper, these favourable properties are attributed to a facile plastic deformation and nano-scale void formation which accommodates the strain. ${ }^{83,84}$ The merit of the mechanical properties of pDCPD was impressively described in a publication on the ballistic performance of pDCPD in comparison with two epoxy-amine systems with comparable glass transition temperatures. pDCPD showed a $300-400 \%$ better penetration resistance in ballistic energy dissipation in a temperature range of -55 to $75{ }^{\circ} \mathrm{C} .{ }^{85}$

The choice of the initiator (together with the processing conditions) not only determines the degree of cross-linking but also the microstructure of the polymer-backbone. While G1 produces rather trans-double bonds, a higher cis-double bond content is obtained with G2. The stereochemistry of the pDCPD backbone is another factor influencing the thermal and mechanical properties of the polymer. A nice showcase paper discussing all these aspects influencing the final properties of, in this case, pDCPD aerogels might be instructive for researchers who wish to become active in this field. ${ }^{86}$ Furthermore, in the context of cis and trans content, it is worth mentioning that molybdenum and tungsten (but no ruthenium) based initiators are known to provide stereospecific ROMP of DCPD, yielding in 
some cases crystalline polymers. ${ }^{87-89}$ Achieving stereospecific ROMP of DCPD with ruthenium based initiators might open the door for materials with better or even new properties.

2.2.2. Durability of pDCPD. The thermal aging of pDCPD is dominated by fast oxygen diffusion limited oxidation affecting the surface to a depth of about 10-100 $\mu \mathrm{m}$. The oxidised volumes feature a higher cross-linking degree, a higher glass transition temperature, an increased hardness and polarity of the surface and reduced swelling. Addition of stabilisers such as Tinuvin ${ }^{\circledR} 171$ leads to an even harder surface layer. These surface layers were shown to protect the bulk material underneath from oxidation. Even unstabilised pDCPD is extremely resistant to bulk-oxidation and is in this context far superior to e.g. poly(propylene). ${ }^{90}$ The high rate of surface oxidation was ascribed to a low apparent activation energy (of only $\left.\approx 45 \mathrm{~kJ} \mathrm{~mol}^{-1}\right)^{91}$ and to the glassy state of pDCPD. The latter feature causes a low termination rate between initially formed peroxy radicals leading to the accumulation of high hydroperoxide concentrations of about $1-2 \mathrm{~mol} \mathrm{~L}^{-1}$ at $50{ }^{\circ} \mathrm{C}$ after about 8 h. ${ }^{92}$ The follow up products from hydroperoxide decomposition are then carboxylic acids, aldehydes, ketones and alcohols as well as newly formed $\mathrm{C}-\mathrm{C}$ bonds. Oxygen incorporation at the surface amounts to approx. 0.5 equiv. $\mathrm{O}_{2}$ per repeat unit. $^{93,94}$ The aging of pDCPD under high temperature and high pressure in seawater was investigated. The results reveal that for aging at temperatures below the glass transition only oxidative degradation occurs, whereas for aging at higher temperatures a secondary polymerisation process of the material is observed. The water absorption of pDCPD was determined to be $1 \%$ (the water diffusion is $8 \times 10^{-13} \mathrm{~m}^{2} \mathrm{~s}^{-1}$ at $25^{\circ} \mathrm{C}$ ) and the mechanical properties are not compromised by water uptake. ${ }^{78}$

2.2.3. Copolymers of pDCPD. Most copolymerisation reactions performed either use cross-linking ROMP-able or chain extending ROMP-able monomers with the aim to tailor the rheological, mechanical and thermal properties of the resulting thermoset. The respective studies are not discussed here but are mentioned where appropriate within the other chapters of this review. Some effort was made to use biobased cross-linking norbornene derivatives as co-monomers and studies on functionalised isosorbide ${ }^{95}$ and castor-oil ${ }^{96,97}$ have been disclosed.

Chain transfer agents are barely used in (materials directed) pDCPD chemistry because they impede the formation of the cross-linked structure or at least decrease the glass transition temperature of the thermoset. Two studies with monoterpenes demonstrate the principle. One publication reported the synthesis of hyperbranched (soluble) pDCPD upon using $\beta$-pinene, limonene oxide or $d$-limonene. ${ }^{98}$ Using less monoterpene the degree of crosslinking of pDCPD was altered and the thermoset was plasticised to a desired degree. ${ }^{99}$ Very low amounts of fluorescent chain transfer agents (not altering the thermal and mechanical properties) were used to study the polymerisation of pDCPD by operando fluorescence microscopy imaging. It was found that the morphology of the precipitated polymers at an early stage persists in the bulk polymer. Strand aggregation was found to be slow and irreversible relative to precipitation. $^{100}$
Another type of copolymerisation makes use of the olefin addition occurring at elevated temperature. Substituted cyclopentadiene $^{101}$ derivatives and substituted maleimide derivatives were employed. ${ }^{102,103}$ Rigid cross-linking monomers enhanced the thermal and dynamic mechanical properties.

Thermoset blends of pDCPD and epoxy resins resulted in macroscopically phase separated systems featuring two glass transition temperatures. In the blend the higher strength of the epoxy resin can be greatly retained while the fracture toughness was increased. ${ }^{104,105}$ The blends were used for gluing carbon fibre reinforced composites with steel. The epoxy-pDCPD blend adhesives realized much higher bond strengths compared to either neat epoxy or neat pDCPD, which was attributed to an increased shear toughness of the blend. ${ }^{106}$ Similarly, the blend of polyethylene wax and pDCPD was studied; here thermally induced cross-linking between pDCPD and the wax was postulated. ${ }^{107}$

2.2.4. Nanocomposites of pDCPD. The improvement of the physical properties of pDCPD takes centre stage in this research. First, it is aimed at enhancing ideally both the strength and toughness of pDCPD. Second, the physical properties of pDCPD are changed according to the needs of specialised applications.

Copolymerisation of polyhedral oligomeric silsesquioxanes with DCPD did not result in significant property changes of the composite material. ${ }^{108}$ However, the use of vinyl-functionalised silica particles (diameter $0.3-0.7 \mu \mathrm{m}$ ) led to a distinct enhancement of the toughness of the materials. Upon just adding $0.2 \mathrm{wt} \%$ of the particles the tensile toughness increased by a factor of 14 , while the yield strengths decreased by about $10 \%$ compared to pDCPD without particles. ${ }^{109}$ In follow-up work, the silica particles have been differently functionalised and the effect of functionalisation on the mechanical properties of pDCPD composite materials was studied. Ethyl-functionalised particles were found to increase the strength and toughness. ${ }^{110-112}$ Poly(styrene) coated silica nanoparticles were shown to decrease the friction coefficient and the wear rate of pDCPD. ${ }^{113,114}$ An older study reports norbornene-capped silica particles and an improved wear resistance of the PDCPD/silica nanocomposite processed by RIM. ${ }^{115}$ Also $\mathrm{MoS}_{2}$ pDCPD nanocomposites were investigated for their wear resistance. ${ }^{116}$ The outstanding dielectric characteristics of pDCPD (which are similar to those of poly(propene)) motivated development of a RIM process allowing further improvement of them. By incorporation of $10 \%$ fumed silica, a permittivity of 2.8 was obtained and the mechanical properties were not compromised significantly. ${ }^{117}$ Another example aiming in the same direction comprised the use of $\mathrm{BaTiO}_{3}$ nanoparticles (5 wt\%) for increasing the permittivity of pDCPD (1.7) to 2.4 whereby the breakdown strength was only reduced by $13 \% .{ }^{118}$ Work on montmorillonite nanocomposites was performed. ${ }^{119-122}$ Most interesting is a contribution in which so-called intergallery-surface-initiated ROMP was used to obtain an exfoliated montmorillonite nanocomposite with $50 \%$ increased stiffness in compression. ${ }^{123}$

The most influential work on pDCPD nanocomposites was published in 2008. Norbornene functionalised multiwalled carbon nanotubes were used in low loadings $(<0.5 \mathrm{wt} \%)$ and the resulting nanocomposites exhibited a slightly enhanced Young's modulus of 2.09-2.14 GPa (neat pDCPD 2.07 GPa) but a 
distinctly enhanced strain at break up to $51.8 \%$ (neat pDCPD $5.75 \%$ ) resulting in a toughness of about $25 \mathrm{MPa}$ (2.44 for the reference). ${ }^{124}$ A different carbon nanotube functionalisation route was disclosed and the derived material tested with DCPD. ${ }^{125,126}$ Non co-polymerisable carbon materials used as nanofillers comprise expanded graphite nanosheets, ${ }^{127}$ vapour grown carbon fibers and graphene oxide. ${ }^{128,129}$

2.2.5. Fibre reinforced pDCPD. Today's composites consist mainly of glass or carbon fibres (mats) embedded into a thermoset matrix based on epoxy- and polyester chemistry. Resin transfer moulding and vacuum infusion are the most frequently used processing methods. pDCPD is an interesting alternative to these conventional matrices, for two main reasons. First, the viscosity of a typical DCPD based resin ( $\approx 10 \mathrm{cPs})$ is similar to that of water and much lower than that of conventional resins. Thus, infiltration of the fibre mats, especially when big parts are manufactured, is less energy and time consuming. Second, pDCPD is less brittle than many other matrices of similar strengths, resulting in an appealing impact resistance. ${ }^{130}$ A pDCPD based glass fibre composite and an equivalent epoxy composite were compared and revealed a greatly superior damage resistance of the pDCPD based parts. ${ }^{131}$ Since interfacial adhesion between the fibres and the matrix is an important factor for the properties of the composites, different glass-fibres were tested. ${ }^{132}$ Silanisation of the glass fibre surface has beneficial effects on interfacial adhesion. ${ }^{133,134}$ Degradation tests of pDCPD glass fibre composites versus epoxy based systems under hygrothermal conditions revealed the superiority of the pDCPD system. The results were rationalised by the lower water uptake of the pDCPD based parts. ${ }^{135,136}$ Thermal aging of glass fibre composites under air caused oxidation of the surface region $(\sim 100 \mu \mathrm{m})$. Aging at $150{ }^{\circ} \mathrm{C}$ induced significant degradation of the fibre-matrix interface, while aging at $100{ }^{\circ} \mathrm{C}$ for 6 months had little effect on the fibre-pDCPD interface properties. ${ }^{137}$ Polyethylene fibre ${ }^{138}$ and carbon fibre reinforcement of pDCPD were also investigated. ${ }^{139,140}$

Another type of filling is aimed at reducing the cost of pDCPD and its use in structural applications. Wollastonite, a cheap filler with a needle-like crystal shape and high thermal stability, was used to prepare composite materials with pDCPD. Up to $67 \mathrm{wt} \%$ of the $\mathrm{CaSiO}_{3}$ mineral was incorporated by planetary mixing and the composites' high compressive strength of more than $100 \mathrm{MPa}$ revealed them to be superior to high strength concrete (63 MPa). ${ }^{141}$ Recently, DCPD-based resins were tested for their ability to penetrate into rocks and to reinforce the rock's mechanical strength. Due to the low viscosity of the resin, the desired diffusion was obtained in dry and 50\% water saturated rocks. Upon curing the storage modulus and the flexural strengths were improved, qualifying the resin for downhole applications such as sealants or plugs. ${ }^{142}$

2.2.6. DCPD as 'glue' in self-healing materials. In service, composite parts are subjected to diverse forces, which cause, besides visible and easily detectable failures, hardly visible or even invisible micro-cracks in the polymer matrix. Therefore, a reduction in fibre-dominated properties such as the tensile strength and other material fatigue occur. ${ }^{143}$ If these micro-cracks coalesce in structural composites, delamination and fibre fracture follow. As a means to mitigate such effects, a selfhealing function can be added to the material. Self-healing is a process by which a damaged material can at least partially restore its original properties. One of the most prominent self-healing strategies relies on ROMP of DCPD and similar strained cyclic olefins. ${ }^{144}$ Healing is accomplished by the stress triggered release of microencapsulated DCPD from a ureaformaldehyde shell ${ }^{145}$ and polymerisation with the initiator, which is embedded in the epoxy-based composite matrix. Initially G1 was used as the initiator but since then many efforts were made to improve the thermal stability, the processability and the activity of the initiator. ${ }^{146-149}$ Thermal stability is of central interest. During curing of the matrix material, the initiator is usually exposed to high temperatures for prolonged times as well as to potential initiator poison (e.g. oxiranes and amines in the case of epoxy-resins). One approach is to encapsulate the initiator (G1) in wax, ${ }^{150,151}$ or to use thermally and chemically more stable variants. ${ }^{152-156}$ Another research direction discloses alternative healing agent carriers such as hollow tubes and fibres, ${ }^{143,144}$ or microvascular networks. ${ }^{157}$ A typical application of self-healing comprises wind turbine blade materials. This is one of the examples in which the idea of self-healing is reasonable, because wind turbine blades face high risks of damage causing high repair costs. ${ }^{158,159}$

\subsection{Emerging processing of pDCPD}

2.3.1. Frontal polymerisation. In frontal polymerisation, a monomer is converted into its polymer directionally in a localized reaction zone. In thermal frontal polymerisation, the polymerisation is started by employing heat and then the polymerisation enthalpy sustains further polymerisation. This leads to transmigration of the polymerisation zone through the volume of the monomer. As a prerequisite, the formulation must have a low rate of polymerisation at the initial temperature but have a very high polymerisation rate at and below the adiabatic polymerisation temperature (which is a technical term for the temperature reached if the polymerisation went to completion without heat loss). The application of frontal polymerisation in the fabrication of fibre-reinforced polymer composite materials is of particularly high interest because of its high energy saving potential. In the light of success in fibrereinforced pDCPD composite materials, DCPD-based frontal polymerisable resins are researched.

In 2001, the first report of frontal Ring-opening Metathesis Polymerisation was published. In this early report, high purity DCPD, G1 and triphenylphosphine as a retarder were introduced. The formulation was prepared above the melting point of DCPD and was then quickly cooled to $27{ }^{\circ} \mathrm{C}$. The actual frontal polymerisation was then performed on solid mixtures. A maximum front temperature of about $205{ }^{\circ} \mathrm{C}$ propagating with a front velocity of $2.6 \mathrm{~cm} \mathrm{~min}^{-1}$ was obtained when the formulation contained 2000 equiv. of DCPD, 1 equiv. of G1 and 2.6 equiv. of triphenylphosphine. ${ }^{23}$ In follow-up work, G2 in combination with 4-dimethylaminopyridine as the retarder was introduced as the initiating system. Maximum front 
temperatures of around $200{ }^{\circ} \mathrm{C}$ were found when the formulation contained 16000 equiv. of DCPD, 1 equiv. of G2 and between 1 and 8 equiv. of 4-dimethylaminopyridine. The variation of the retarder's concentration led to different front velocities, which were between 7.5 and $2.2 \mathrm{~cm} \mathrm{~min}^{-1}$. The pot life of the liquid formulation (toluene was used to keep DCPD liquid) was improved to about $20-30 \mathrm{~min} .{ }^{160}$ As an alternative to 4-dimethylaminopyridine, limonene was tested as a retarding agent. Limonene is a chain transfer agent and thus, albeit frontal polymerisation was feasible, the desired mechanical properties of pDCPD were lost. ${ }^{161}$ Highly reactive exo-DCPD has been tested as a monomer in frontal polymerisation with $\mathbf{G} 2$ decelerated by 4-dimethylaminopyridine. Low G2 loadings of $10 \mathrm{ppm}$ were sufficient to provide frontal polymerisation in this case. However, the pot life of these formulations was still about $20 \mathrm{~min}^{162}$ The pot life issue was tackled by using aliphatic phosphite ester derivatives as retarders for G2. By varying the phosphite ester structure and concentration, a pot life of (endo-)DCPD-based formulations between 0.25 and $30 \mathrm{~h}$ was obtained while still allowing the frontal polymerisation to proceed. The velocity can be adjusted between 1 and $8 \mathrm{~cm} \mathrm{~min}^{-1}$ (Fig. 4). ${ }^{28}$ Such a high pot life is the key for industrial applicability and the same group demonstrated the rapid fabrication of parts with microscale features and carbon-fibre-reinforced polymer composites. The mechanical properties of such processed parts are similar to those of pDCPD cured under conventional conditions. Accordingly, frontal polymerisation processing allows for reducing energy requirements and cure times. Especially for the processing of fibre-reinforced polymer composites a huge saving of time and energy is achieved when compared to conventional epoxy-based parts. Furthermore, three-dimensional printed structures can be fabricated with these formulations. Upon tuning the retarder concentration, free-standing elastomeric gels containing prepolymerised DCPD are obtained. These gels can be extruded from a print head and frontally polymerised upon applying heat to the substrate. In such a process, simultaneous free-form printing of thermosets is achieved. ${ }^{163}$ Numerical studies of the initiation and propagation of the polymerisation front in fibre-reinforced composites were conducted to better understand frontal polymerisation of DCPD. ${ }^{164}$ Lately, the frontal copolymerisation of DCPD with other norbornene derivatives was disclosed with the aim to tune the material properties and simultaneously improve the efficiency in FROMP-based material manufacturing. In doing so, an unexpected increase in the front

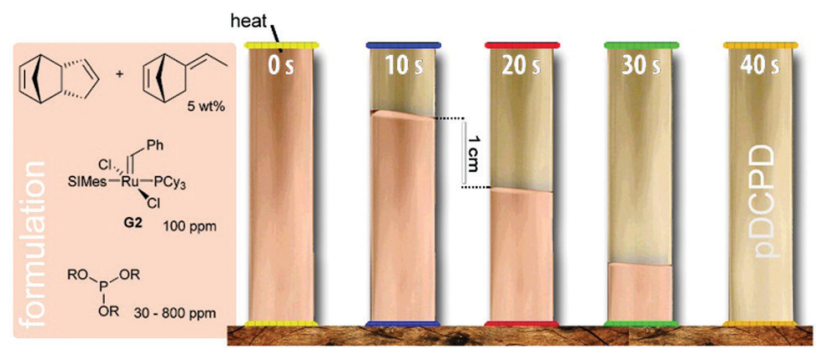

Fig. 4 Frontal polymerisation of pDCPD according to ref. 28. velocity when copolymerising DCPD with dinorbornenyl crosslinking monomers was found and rationalized. ${ }^{165}$

2.3.2. Additive manufacturing of pDCPD. Possibilities for additive manufacturing comprise the already mentioned stereolithographic process ${ }^{64}$ and frontal polymerisation based direct ink-writing. ${ }^{163}$ The latter was further improved towards $3 \mathrm{D}$ printing of thermally insulated pDCPD. The effect of the extrusion pressure and operating temperature on the thermal properties and the surface morphology of the printed pDCPD was studied and a thermal conductivity of $0.1 \mathrm{~W} \mathrm{~m}^{-1} \mathrm{~K}^{-1}$ was obtained under optimised conditions. ${ }^{166}$

2.3.3. Miscellaneous processing of pDCPD. Electrospinning was used to produce sub-micrometre thick fibres of pDCPD. The spinning solution was composed of DCPD, dichloromethane and G2. An aged solution exhibiting the proper viscosity was then used for electrospinning. Electrospinning was only possible in a limited time frame due to the rapidly changing viscosity of the solution. However, these fibres collected exhibited Young's moduli larger than the typical values for bulk pDCPD. ${ }^{167}$

Another processing method is surface-initiated ROMP from the vapour phase. The first report used, amongst other monomers, DCPD from the vapour phase for patterned growth of pDCPD on surfaces with microcontact printed and physisorbed G2. ${ }^{168}$ Later, surface initiated ROMP of exo- and endo-DCPD was studied using initiators covalently attached to gold and silicon substrates. Approx. $400 \mathrm{~nm}$ thick pDCPD films were obtained in less than 1 min of polymerisation and no significant differences in thickness were observed for the different stereoisomers. Film thicknesses ranging from tens of nanometres to hundreds of nanometres could be achieved upon adding decane as an unreactive diluent to the vapour phase. The films provide effective barriers to the diffusion of aqueous ions in excess of $1 \times 10^{6} \Omega \mathrm{cm}^{2}$ and exhibit a reduced Young's modulus of $15 \mathrm{GPa}^{70}$

Finally, the polymerisation of DCPD in a microemulsion leading to stable pDCPD latexes which can be further processed should be noted. Water soluble, acid switchable initiators were used to polymerise DCPD (and DCPD/cyclooctene mixtures) in an Emulgin ${ }^{\circledR}$ B3 stabilised microemulsion. With low initiator loadings of about $200 \mathrm{ppm}$, almost complete polymerisation was found and stable latexes with particle diameters ranging from $255 \mathrm{~nm}$ to $315 \mathrm{~nm}$ and low coagulate content were obtained. ${ }^{54}$ Prior work disclosed carbon nanotube loaded latexes. ${ }^{169}$ Another emulsion based approach is the preparation of particles featuring interfacially assembled nanoparticle-conjugated lipase. Such $10 \mu \mathrm{m}$ big functional particles in which PDCPD serves as the glue displayed an increase in catalytic efficiency of the lipase when compared to the native enzyme. The particles could be magnetically recovered, thanks to the magnetic nanoparticles used. Moreover, the immobilized lipase exhibited enhanced thermal and $\mathrm{pH}$ stability ${ }^{170,171}$ and could be operated in deep eutectic solvents. ${ }^{172}$

\subsection{Porous pDCPD}

2.4.1. Macroporous pDCPD by chemically induced phase separation. Chemically induced phase separation (also named chemical cooling, polymerisation-induced phase separation or 


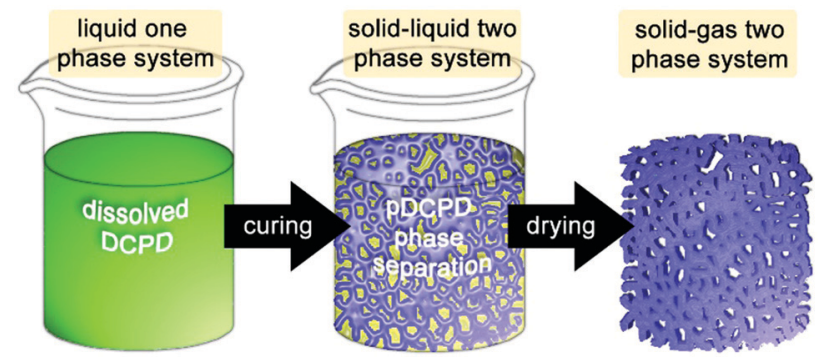

Fig. 5 Cartoon of the process chemically induced phase separation for the preparation of macroporous PDCPD.

reaction-induced phase separation) is a method to produce macroporous thermosets used e.g. in separation applications. Essentially, this methodology is based on polymerising a monomer dissolved in a solvent which is a bad solvent for the created polymer. The initially homogeneous solution phaseseparates upon polymerisation and eventually the solvent is removed, generating a macroporous structure (Fig. 5).

For DCPD, 2-propanol is a suitable solvent for this purpose and allows for preparing closed or open cell porous monoliths depending of the 2-propanol share. Above $30 \mathrm{wt} \%$ of 2-propanol content, the porous structure consists of agglomerated spherical pDCPD particles (of about 3-4 $\mu \mathrm{m}$ ). Porosities of up to $80 \%$ were obtained ${ }^{173}$ and monoliths exhibiting a gradient porosity were accessible. ${ }^{174}$ Additionally adding norbornenefunctionalized poly(ethylene glycol) oligomers allowed for a decrease in the pore size and a related increase in the internal surface area. ${ }^{175}$

However, for many applications, the modification of the surface is desirable, if not necessary. The surface grafting of initiators for atom transfer radical polymerisation has been demonstrated and used to graft dense poly(methylmethacrylate) onto pDCPD. The process comprises three steps, with the thiol-ene reaction of mercaptoethanol with the double bonds of PDCPD being the key step. ${ }^{176}$ Furthermore, the double bonds can be brominated (forming a 100-200 nm thick brominated layer) and it has been demonstrated that subsequent nucleophilic substitution with amines yields monolayers on pDCPD. ${ }^{177}$ Epoxidation with $m$-chloroperoxybenzoic acid generates an approx. $10 \mathrm{~nm}$ thick layer of oxiranes. Subsequent ring opening with amines provides the installation of the desired functionality in a second step. ${ }^{178}$

2.4.2. Macroporous PDCPD by emulsion templating. An alternative way to prepare macroporous polymers is high internal phase templating. In this case the liquid monomer used as the minority phase should be immiscible in another liquid (the majority component, typically $80-99 \mathrm{vol} \%$ is used) and upon addition of a suitable surfactant and agitation a high internal phase emulsion forms. In such an ideally kinetically stable situation, the majority phase forms droplets within the continuous phase made up by the monomer. Then the initiator is added and the emulsion is cured in a mould. After solidification of the continuous phase, the majority phase is removed, typically resulting in fully opened polymer foams containing spherical voids (of several $\mu \mathrm{m}$ in diameter) interconnected by windows (Fig. 6). ${ }^{179}$

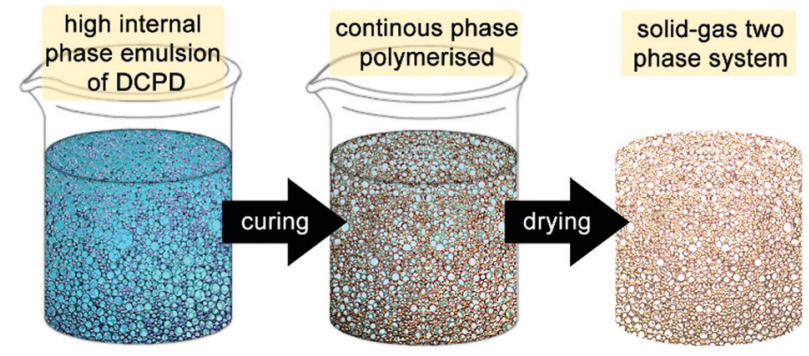

Fig. 6 Cartoon of the high internal phase emulsion templating route to prepare open porous macroporous foams.

The first attempt to template DCPD failed, presumably due to an insufficient emulsion stability at the elevated temperature needed for curing. ${ }^{180}$ However, using water as the majority phase, Pluronics L-121 as the surfactant and M2 as the initiator enables the preparation of high internal phase templated DCPD of about $80 \%$ porosity and exceptional mechanical properties compared to other high internal phase templated polymers. ${ }^{181}$ However, it was realized that the PDCPD monoliths quickly and fully oxidise at elevated temperature under ambient conditions yielding a polymer with an empiric sum formula of $\mathrm{C}_{5.2} \mathrm{H}_{6.4} \mathrm{O}_{1.9}$. The oxidation goes in hand with a stiffening of the foam. Nevertheless, the liability of oxidation constitutes the material's Achilles heel in many potential applications. Upon varying the DCPD to water ratio from $50: 50$ to $20: 80$ open porous monolithic polymers of different porosities could be prepared, whereby the openness of the foams of low porosity is a peculiarity within high internal phase templated polymers. ${ }^{182}$ The feature sizes of the foam, i.e. void and window sizes, can be determined upon variation of the surfactant amount (10-0.25 vol\% with respect to DCPD). Void sizes between 3 and $70 \mu \mathrm{m}$ can be obtained. Thereby it was revealed that the mechanical properties of the foams are distinctly dependent on the surfactant amount used. Especially when reducing the surfactant amount below generally accepted values in the field, ductile open porous polymer foams with $80 \%$ porosity and Young's moduli of about $110 \mathrm{MPa}$ were prepared. ${ }^{183}$ A comprehensive investigation of the mechanical properties of unoxidised pDCPD foams of $90-50 \%$ porosity using tensile testing revealed Young's moduli between 31 and $416 \mathrm{MPa}$ and moduli of toughness between $600 \mathrm{~kJ} \mathrm{~m}^{-3}$ and $2 \mathrm{MJ} \mathrm{m}{ }^{-3} \cdot{ }^{184}$ Similarly, membranes are easily accessible by doctor blading. Open-cellular macroporous membranes with about $80 \%$ porosity and $180 \mu \mathrm{m}$ thickness are characterized by a Young's modulus of about $125 \mathrm{MPa}$ and an ultimate strength of 3.1 MPa at an elongation of about $20 \%{ }^{185}$

Similar membranes obtained from copolymerizing norbornene and DCPD were used as separators in lithium-ion batteries. A comparison with cells made from conventional poly(ethylene)-based separators revealed their applicability despite the presence of unsaturation in the polymer backbone. The combination of the high porosity and good wettability of the separators suggests that such considerably thick separators might be useful in bigger lithium-ion batteries with increased safety issues. ${ }^{186}$ Like in the case of the separators, copolymerisation of 
other ROMP-able monomers has been studied and its effects on the mechanical properties ${ }^{187,188}$ and the foam's swelling behaviour have been disclosed. ${ }^{188}$

Amongst copolymerisation, the properties of the foams can be influenced upon the addition of inorganic nanoparticles. Magnetic foams were obtained by adding up to $30 \mathrm{wt} \% \gamma \mathrm{Fe}_{2} \mathrm{O}_{3} /$ $\mathrm{Fe}_{3} \mathrm{O}_{4}$ nanoparticles to the emulsion and subsequent curing. The oxides were mainly found at the surface of the polymeric phase and the good casting quality of the samples was maintained. Burning off the polymeric phase yielded macroporous $\mathrm{Fe}_{2} \mathrm{O}_{3}$, demonstrating a way towards high internal phase templated ceramics. ${ }^{189}$ Similarly, zinc oxide nanoparticles were used to prepare pDCPD nanocomposite foams. Subsequent calcination yielded macroporous $\mathrm{ZnO}$ foams, which showed an appealing catalytic performance in the catalytic wet air oxidation of bisphenol A. ${ }^{190}$ Furthermore, TiO ${ }_{2} @$ pDCPD has been described and tested in the photocatalytic degradation of 4-nitrophenol. ${ }^{191}$ Later, the composite foam's mechanical properties with and without antioxidants have been disclosed. ${ }^{192}$ In another study, nanoparticular metal-organic frameworks (MOFs) were used to obtain $100 \mu \mathrm{m}$ thick, fully open, hierarchically porous hybrid membranes. Up to $14 \mathrm{wt} \%$ of MIL-100(Fe) nanoparticles were incorporated, resulting in an increase of the microporosity from 5 to about $130 \mathrm{~m}^{2} \mathrm{~g}^{-1}$. The MIL100(Fe)@pDCPD membranes showed an appealing catalytic activity in Friedel-Crafts alkylation in batch and flow-through mode, thereby demonstrating the preserved accessibility of Lewis acidic sites in the MOF. ${ }^{193}$ Another study utilized $\mathrm{CuO}$ and ZnO@pDCPD foams to grow MOFs (HKUST-1(Cu) and MOF-5(Zn)) upon addition of ligand solutions. In this way, up to about $75 \mathrm{wt} \%$ MOF loading of the foams was obtained and micropore accessibility was greatly retained. The hydrolytical instability of the MOFs was distinctly reduced in the MOF@pDCPD composites. This feature enabled the preservation of the composite's $\mathrm{CO}_{2}$ sorption capacity under humid conditions for at least 20 cycles. ${ }^{194}$ Another example of stabilization within macroporous pDCPD foams comes from encapsulating enzymes. Lipase was incorporated into pDCPD foams upon adding the enzyme to the aqueous phase of the high internal phase emulsion. Curing was done at room temperature and the encapsulated lipase was found to be active under harsh reaction conditions not complying with free lipase. Further, the lipase@pDCPD retains over 50\% activity after 10 cycles of reuse. ${ }^{195}$ The above mentioned high internal phase emulsion approach was initiated to resolve recovery issues of $10 \mu \mathrm{m}$ big pDCPD particles with interfacially assembled nanoparticleconjugated lipase mentioned above. ${ }^{170}$

Post-polymerisation functionalization of emulsion templated pDCPD in the unoxidised state was performed with epoxidation, ${ }^{196}$ bromination, ${ }^{185}$ thiol-ene ${ }^{181}$ and inverse electron demand Diels-Alder reactions. In the latter approach, tetrazines (e.g. 3,6-di(pyridin-2-yl)-1,2,4,5-tetrazine) were reacted with the double bonds of pDCPD foams resulting in functionalisation of up to every second repeating unit with a potential metal chelating ligand. ${ }^{197}$ The same reaction was also used with linear pDCPD and the gelation of the resulting polymer with metal ions was studied. ${ }^{198}$ Epoxidation of pDCPD monoliths was performed in supercritical $\mathrm{CO}_{2}$. In that respect, it was revealed that the foams exhibit an unusually high uptake of $\mathrm{scCO}_{2}$ at zero swelling. The $\mathrm{scCO}_{2}$ treatment creates additional mesoporosity within the foam walls and a sequence of epoxidation followed by aminolysis with ethylenediamine yielded $11.4 \mathrm{mmol} \mathrm{g}^{-1}$ of nitrogen incorporated into the foam walls. ${ }^{196}$

As already mentioned, pristine pDCPD foams react with elemental oxygen from air yielding (amongst other functional groups) stable hydroperoxide moieties within the polymer scaffold. The hydroperoxide-containing pDCPD foams were then used to oxidise and sequester Demeton-S and 2-chloroethyl ethyl sulphide, employed as models for chemical warfare agents. The simplicity of the detoxification is believed to hold high promise for the development of self-decontaminating filter media. ${ }^{199,200}$ Another exploitation of the porous material's high tendency to oxidize was its use as an oxygen scavenger material. However, in this application emulsion templated poly(norbornadiene) proved superior to emulsion templated pDCPD. ${ }^{201}$ Oxidation in air leads to a stiffening of the macroporous monolithic specimens to such a degree that their cellular structure is not lost upon heating (up to $1400{ }^{\circ} \mathrm{C}$ ) under an inert atmosphere. Thus, the 'fixation' upon oxidation allowed for the preparation of monolithic open macroporous carbons of $80-85 \%$ porosity featuring void diameters in the range of 87 to $2.5 \mu \mathrm{m}$. The porous carbon materials were characterized by carbon contents higher than $97 \%$, electronic conductivities of up to $2800 \mathrm{~S} \mathrm{~m}^{-1}$, Young's moduli of up to $2.1 \mathrm{GPa}$ and specific surface areas of up to $1200 \mathrm{~m}^{2} \mathrm{~g}^{-1}$. All these values were mainly depending on the carbonisation conditions. ${ }^{202}$

2.4.3. Aero- and xerogels made of pDCPD. Aerogels are typically obtained by supercritical drying of wet polymer gels and generally feature extremely low density, high surface areas and attractive dielectric, thermal and acoustic properties. Upon supercritical drying shrinking occurs and aerogels lose about $10 \%$ of their initial volume (Fig. 7).

Alternatively, ambient pressure drying processes are employed. In this case the volume shrinkage is much bigger (typically 50\%) and pore structure damage occurs. High capillary forces are responsible for this phenomenon. The first pDCPD based aerogels were published in 2007 and were obtained by polymerizing a solution of DCPD with G1 targeting an aerogel density of $0.06 \mathrm{~g} \mathrm{~cm}^{-3}$. The system was further investigated by varying the target density, the initiator loading, the solvent

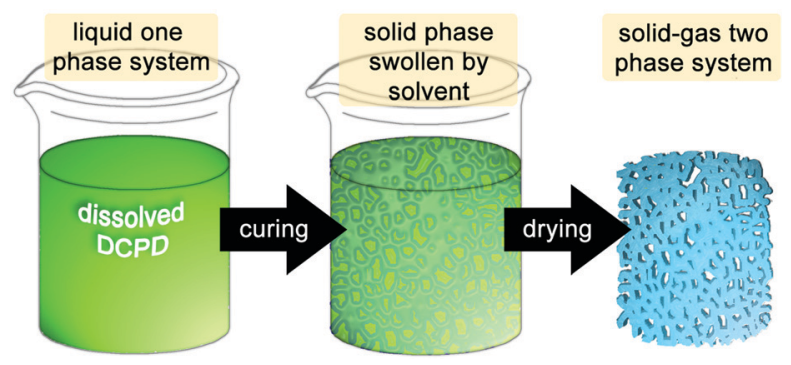

Fig. 7 Schematic preparation of aerogels. 
and the drying conditions (supercritical $\mathrm{CO}_{2}$ drying $v s$. conventional drying). Typical pDCPD aerogels obtained within this study were characterized by a density of $0.06 \mathrm{~g} \mathrm{~cm}^{-3}$, a pore volume of $0.89 \mathrm{~cm}^{3} \mathrm{~g}^{-1}$, an average pore diameter of $15 \mathrm{~nm}$, a surface area of $235 \mathrm{~m}^{2} \mathrm{~g}^{-1}$ and a thermal conductivity of $22.9 \mathrm{~mW} \mathrm{mK}^{-1}$. However, the preparation of homogenous and uniform specimens was difficult to achieve. ${ }^{203}$ Key to improving this issue is precise control over the viscosity and gel time and gelation can be manipulated by reducing the amount of cross-linking through co-polymerisation with a non-crosslinking monomer. It was shown that only small additions of norbornene (1-10 wt\%) increase the viscosity at the sol-gel transition by several orders of magnitude, resulting in better uniformity of the samples. The finding was applied to the coating of cylindrical and spherical surfaces with pDCDP aerogel films, which is particularly challenging because shear forces can additionally damage the growing gel network. ${ }^{204}$ This work was further extended towards other non-crosslinking but functionalized monomers (e.g. Fig. 8, $\mathrm{R}=\mathrm{CH}_{2} \mathrm{I}$ ) and the effect of functionalisation on the morphology of the aerogels was studied. ${ }^{205}$ Post-polymerisation iodation (and bromination) was tried in a forthcoming study. Because only limited control over the amount and the uniformity of halide incorporation was obtained, the incorporation of iodide (and also tributyltin) groups was preferably accomplished via copolymerisation of accordingly substituted norbornene derivatives. Such obtained aerogels were aimed at providing high- $Z$ tracer element substituted organic aerogels for use in inertial confinement fusion. ${ }^{206}$

Switching from G1 to $\mathbf{G 2}$ as the initiator caused severe deformation of the wet gels during processing (swelling in toluene) yielding aerogels unsuitable for any application. This issue was resolved by performing free radical polymerisation of methyl methacrylate in the pores of the wet gel and welldefined aerogels could be obtained. ${ }^{207}$ The phenomenon is explained by a synergism related to the nano-topology of the

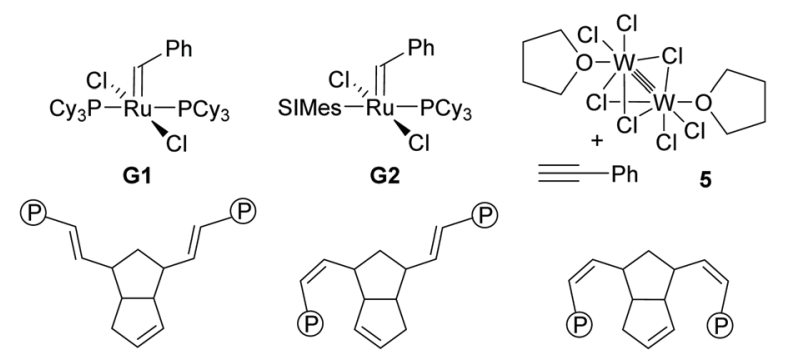

trans-double bond content swelling in toluene

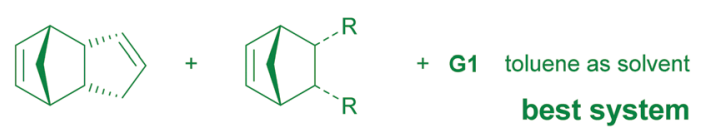

Fig. 8 Initiators used for the preparation of aerogels and the preferred stereochemistry of the double-bond in the repeating unit, being decisive for the aptitude in aerogel synthesis; the best systems are late gelating mixtures of DCPD with less than 10 mol\% non-crosslinking monomer $\left(\mathrm{R}=\mathrm{H}, \mathrm{CH}_{2} \mathrm{l}, \mathrm{Sn}\left({ }^{n} \mathrm{Bu}\right)_{3}\right)$ cured with $\mathrm{G} 1$ in toluene. two components. It was shown that upon drying the macroscopic deformation of wet gels is accompanied by coalescence of initially formed polymer-nanoparticles that form non-massfractal secondary particles. While in the case of neat PDCPD it is believed that these secondary particles further rearrange in such a way that the secondary particles move in the empty space of the others, this movement is impeded in the presence of poly(methyl methacrylate) and thus the structure is better conserved. ${ }^{208}$ Operando fluorescence microscopy imaging supported the findings. ${ }^{100}$ On a molecular level, this behaviour was attributed to the higher trans-content of PDCPD polymerised with G1 when compared to PDCPD made with G2. It was concluded that higher trans-content makes PDCPD more rigid, while higher cis-content results in increased malleability. ${ }^{86}$ Accordingly, the swelling of cis-enriched pDCPD (in a nonpolar solvent) should be higher than of trans-enriched pDCPD. Indeed, preparing xerogels with the initiator-systems $\mathrm{Na}\left[\mathrm{W}_{2}\left(\mu-\mathrm{Cl}_{3}\right)_{3} \mathrm{Cl}_{4}(\mathrm{THF})_{2}\right]$ $(\mathrm{THF})_{3} /$ phenylacetylene (5) yielded heavily deformed specimens with high cis-content. Their swelling in toluene was studied and compared to samples prepared with G1. The xerogels prepared with 5 increased their volume by more than a factor of 100, while xerogels obtained from G1 did not swell at all. ${ }^{209}$ The swelling behaviour of the 5-retrieved pDCPD xerogel was further studied using 44 different solvents. From these data, the Hansen solubility parameters and the Flory-Huggins parameter $\chi_{12}$ of mostly cis PDCPD were derived. The xerogels were particularly useful for separating chloroform from water. ${ }^{210,211}$

As is the case for all other porous pDCDP variants, also the aerogels are prone to oxidative degradation under ambient conditions. Although the oxidized variants have never been studied, an approach to mitigate this issue was published. Upon hydrogenation with $p$-toluenesufonyl hydrazide, hydrogenated pDCPD aerogels became accessible. The improved oxidative stability was proven by thermolysis studies at $135{ }^{\circ} \mathrm{C}$ for $2 \mathrm{~h}$ under ambient conditions. While the pDCPD samples turned brownish and shrank and oxidation products were identified, the hydrogenated versions stayed colourless and no typical pDCPD oxidation products were observed in the infrared spectra. However, also the hydrogenated aerogels shrank considerably during the thermal treatment. ${ }^{212}$

2.4.4. Nanoporous membranes from DCPD only. Solid, dense membranes fabricated from DCPD (5000 equiv.) polymerised by G1 (1 equiv.) allow for separating molecules with molecular weights of $100-600 \mathrm{~g} \mathrm{~mol}^{-1}$ based on the concept of crosssectional area cut-off (and not based on molecular weight cut-off usually used in organic solvent nanofiltration). It was reasoned that swollen membranes feature polydisperse subnano- to nanometer-sized openings between the polymer chains allowing small molecules to diffuse through. Molecules with cross-sectional areas above $0.50 \mathrm{~nm}^{2}$ permeated with a flux $10^{4}$ to $10^{5}$ times slower than molecules with cross-sectional areas below $0.40 \mathrm{~nm}^{2}{ }^{213}$ This finding was utilized to separate palladium complexes and phosphines used in Buchwald-Hartwig and Sonogashira coupling reactions from the products by simple nanofiltration. ${ }^{214}$ Similarly, the separation of mixtures of fatty acid triisobutylamine salts by such organic solvent 
nanofiltration membranes was studied. Bigger cis-fatty acid salts (oleic, petroselinic, vaccenic, linoleic, and linolenic acid) could be separated from smaller saturated (stearic acid) and trans-fatty acid (elaidic acid) salts based on their cross-sectional areas. A pressure-accelerated process for obtaining fluxes sufficient for industrial purification facilities was developed. ${ }^{215}$

2.4.5. Membranes from DCPD and reactive block-copolymers. Membranes with bigger pores have been prepared by combining polymerisation-induced phase separation and block-copolymer templating. Specifically, a mixture of a norbornene-functionalized poly(styrene)-poly(lactide) diblock copolymer (6) and DCPD in tetrahydrofuran was polymerized and the etchable polylactide block was then removed upon treatment with $\mathrm{NaOH}$ (Fig. 9). The resulting membranes featured remarkable mechanical properties (Young's modulus close to $1 \mathrm{GPa}$, ultimate strength of about $30 \mathrm{MPa}$ at an elongation of roughly $10 \%$ ) and a bicontinous structure percolating throughout the membrane. The average pore diameter was around $20 \mathrm{~nm}$ and the material featured a narrow pore size distribution. ${ }^{216,217}$ Gas and liquid transport measurements through such membranes were performed and revealed their suitability for ultrafiltration. The molecular weight cut-offs can be tuned by changing the size of the constituent blocks in the templating copolymer. ${ }^{218}$ Only polymerising a mixture of the norbornene-functionalized poly(styrene)poly(lactide) diblock copolymer and DCPD (i.e. leaving out the solvent) led to the formation of nanoporous monoliths with aligned cylindrical domains. The alignment was obtained by pressing the blend of unpolymerised (macro)monomers through

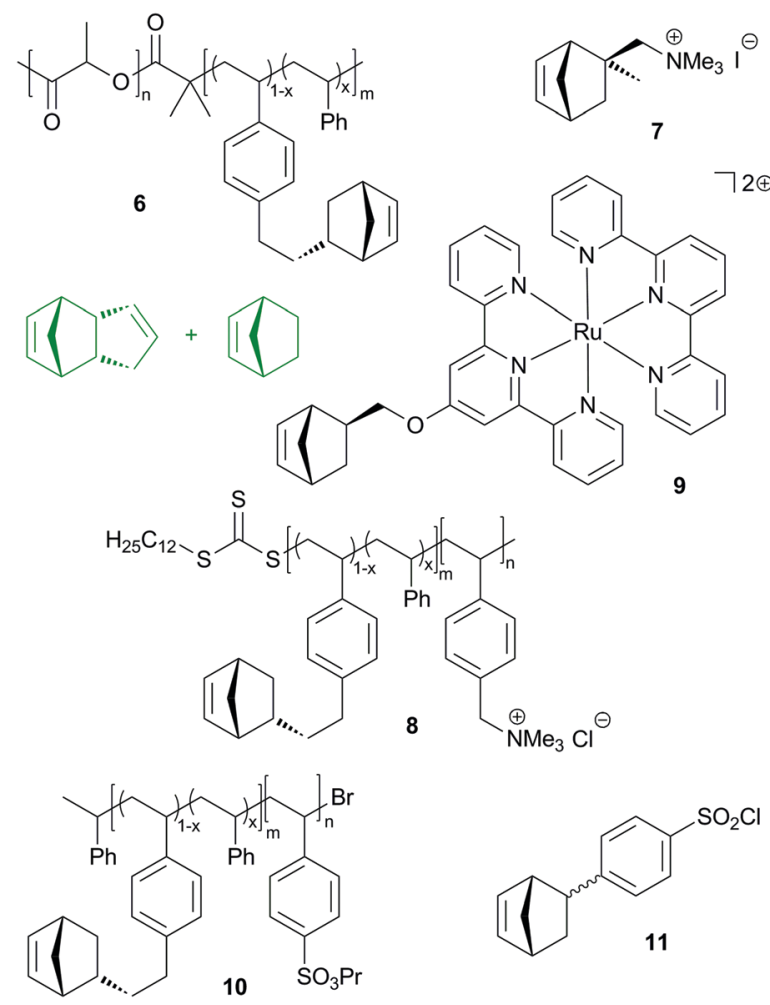

Fig. 9 Structural (in green) and functional (macro)monomers used for the preparation of nanoporous membranes. a channel before polymerisation occurred. Retardation of the polymerisation was necessary and was accomplished by adding triphenylphosphine to the initiator (G1). Upon etching away the poly(lactide)-block, monoliths featuring a specific surface area of about $130 \mathrm{~m}^{2} \mathrm{~g}^{-1}$, pore diameters on the order of $10 \mathrm{~nm}$ and similarly good mechanical properties to those described for solvent-borne membranes were obtained. ${ }^{219}$ Changing the reactive diblock-copolymer used above for a specially designed triblock-copolymer allowed for the preparation of stimuli responsive porous membranes. ${ }^{20}$

2.4.6. Anion exchange membranes. Research on alkaline anion exchange membranes targets mainly the use in alkaline fuel cells. The reduction of cost and methanol crossover is envisaged. pDCPD based permanently cationic membranes are a particular class of materials in this context. In a first report in 2009 tetraalkylammonium-functionalized norbornene (7) was copolymerized with DCPD in chloroform and upon casting and heating the solvent evaporated, yielding thin films. Exchange of the iodine counterion for hydroxide gave the alkaline anion exchange membranes. A composition of 1 part DCPD to 0.5-1 part 7 delivered the best results with respect to mechanical integrity (ultimate strength between 16 and $2 \mathrm{MPa}$ at an elongation of roughly 7-26\%) and hydroxyl conductivity (14-18 $\mathrm{mS} \mathrm{cm}^{-1}$ at $20{ }^{\circ} \mathrm{C}$ ). Dimensional swelling in methanol at $60{ }^{\circ} \mathrm{C}$ was negligible. ${ }^{221}$

Similarly to the reactive diblock-copolymer discussed above, macromonomer $\mathbf{8}$ was used in the copolymerisation with a mixture of DCPD and cyclooctene, yielding membranes that have a bicontinous morphology. In other words, a hydrophobic network featuring hydrophilic conduction paths was established. The resulting membranes exhibited hydroxide conduction as high as $120 \mathrm{mS} \mathrm{cm}^{-1}$ in water at $60{ }^{\circ} \mathrm{C}$. However, their mechanical properties were not sufficient for practical applications. $^{222}$ This issue was resolved by roughly doubling the molecular mass of the diblock-copolymer. In this case, the conductivity dropped to a still high $98 \mathrm{mS} \mathrm{cm}^{-1}$. Controlled membrane swelling led to about $120 \%$ wt $\%$ water uptake, whereby the membrane's mechanical integrity prevented excessive water uptake. Qualifications in fuel cells were performed and resulted in increased power and current density compared to a commercial Tokuyama A201 membrane tested under the same conditions. ${ }^{223}$

Divalent bis(terpyridine)ruthenium(II) based monomer 9 and DCPD were used to prepare membranes as outlined in the previous studies. The DCPD to 9 molar ratios employed were $2: 1,5: 1$ and $10: 1$. Hydrogen carbonate and hydroxide conductivities (19.6, 28.6 and $27.0 \mathrm{mS} \mathrm{cm}{ }^{-1}$ at $30{ }^{\circ} \mathrm{C}$ ) were measured as well as the mechanical properties (ultimate strength between 0.6 and $27 \mathrm{MPa}$ at an elongation of roughly $53-87 \%)$. Swelling tests in aqueous methanol suggested good methanol tolerance. ${ }^{24}$ In a next step, the same group made clear that the conductivity and hydration are dominated by the extent of cross-linking of the membranes. ${ }^{225}$ In a further study, the polymer architecture was slightly changed by using norbornene as an additional co-monomer and, most importantly, ruthenium, nickel and cobalt bis(terpyridine) complexes were employed. 
While the water uptake, mechanical properties and chemical stability were greatly uninfluenced by the use of the different metal complexes, a high impact on conductivity was found. More earth abundant nickel was identified as a competitive alternative to ruthenium. ${ }^{226}$ This discovery was further investigated with the aim to explain differences in anion exchange membranes in general. Isothermal titration calorimetry was employed and indicated a weaker cation-counterion association in the case of the nickel complex. ${ }^{227}$

2.4.7. Proton exchange membranes. Amongst anion exchange membranes, also proton exchange membranes aimed at substituting Nafion ${ }^{\circledR}$ in e.g. direct methanol fuel cells were investigated. Macromonomer 10 was copolymerised with DCPD and/or cyclooctene and upon alkaline hydrolysis followed by acidification proton exchange membranes were obtained. They featured a bicontinous morphology with continuous and size tuneable domains of the sulfonic acid phase and a continuous hydrocarbon phase. The latter phase provides the membranes' mechanical robustness and controls the swellability. ${ }^{228}$ The same membranes were also investigated for their ammonia selectivity versus nitrogen. ${ }^{229}$

More recently, benzenesulfonyl chloride bearing norbornene (11), DCPD and norbornene were copolymerized yielding upon hydrolysis 100-120 nm thick membranes. DCPD served as a crosslinker and increasing crosslinking decreased the proton conductivity, water uptake and swelling ratio, while the selectivity (proton conductivity vs. methanol permeability) increased with increasing crosslinking. ${ }^{230}$ Another group additionally incorporated carboxylic acid groups into the membrane. ${ }^{231}$

In summary of this section, it can be stated that several highly promising nanoporous membranes based on DCPD have been disclosed. However, in the face of the high tendency of DCPD based porous materials to oxidize, their long-term performance is in question. Studies on the oxidation of nanoporous DCPD are definitely missing.

\subsection{DCPD derivatives}

In general, it is not easy to functionalise DCPD without compromising its polymerisability via ROMP and only two functionalized polymerisable DCPD derivative families have been disclosed so far (Fig. 10). The first example (12) is derived from heterodimerisation of carboxylated cyclopentadiene with cyclopentadiene. ROMP with G2 yields a linear homopolymer, which can be thermally cross-linked in a subsequent step. The cross-linked polymer exhibits glass transition temperatures higher than $170{ }^{\circ} \mathrm{C}^{232}$ Based on extensive studies, a radical process was identified to be responsible for the crosslinking reaction. ${ }^{233}$ The processability by RIM of the liquid monomer was demonstrated and similar storage and loss moduli to those for pDCPD were found. ${ }^{234}$

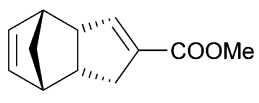

12

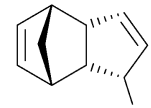

OR 13
Fig. 10 Functionalised DCPD derivatives.
The other monomer family (13) is based on oxidizing the methylene group of the cyclopentene ring in DCPD. Initially, the acetylated monomer was reported in the polymerisation with G1 yielding a linear polymer characterized by higher glass transition temperatures but lower thermal stability when compared to pDCPD. ${ }^{235}$ Later, the parent alcohol, alkyl ethers and esters were polymerised (now with G2 in a solvent free variant) and the obtained cross-linked polymers were characterised via differential scanning calorimetry, thermogravimetric analysis and dynamic mechanical analysis. ${ }^{236,237}$ Generally, the polymerisation of the functionalised DCPD monomers is decelerated in comparison with DCPD. Taking the tedious preparation of both monomer types into consideration, weighty reasons for their application (instead of DCPD) are needed. Their main advantage might be their reduced volatility and smell with respect to DCPD. In some applications, the use of DCPD is limited because of its unpleasant odour. ${ }^{238,239}$ This issue might be resolved with functionalized DCPD derivatives. ${ }^{240}$

\section{Challenges and perspectives}

One of the main challenges in pDCPD chemistry and technology is, according to the judgement of the authors, to get control over the olefin addition based cross-linking at high temperatures. This process leads to steadily growing embrittlement and is particularly problematic in fibre based composite materials. The means to 'freeze' this process at a desired point (i.e. the desired cross-linking density) would be highly desirable. While oxidation seems not to be a big issue for many applications - in fact, the self-passivation of pDCPD is often rather an advantage it has been ascertained as a core problem for many porous variants of pDCPD. Membranes and monoliths will drastically change their properties upon oxidation and will most probably lose their applicability. Although several examples of making use of oxidised porous pDCPD have been shown, the means to protect pDCPD from oxidising is desperately needed.

As regards initiators, gaining control over the stereochemistry of the double bonds and the tacticity with robust initiators is desirable. Additionally, initiators should be well soluble in DCPD, facilitating preparation. Photoinitiators operating in the visible at low loadings should be another target.

The fields of nanocomposites and fibre reinforced composites are going their way. Emphasis, however, should also be laid on finding cheap and practical solutions as soon as the principles are nailed down.

Frontal polymerisation of pDCPD is an emerging processing technology with great potential to revolutionise manufacturing. The same applies to the far less mature additive manufacturing processes not relying on frontal polymerisation. Fast stereolithographic fabrication of pDCPD parts would certainly spark great interest. Another emerging issue comprises research towards reprocessing of densely cross-linked thermoset pDCPD. Recently, a first study on the triggered degradation of pDCPD copolymerised with cyclic silyl ether-based monomers was uploaded to a preprint server. It is expected that the 
recyclability of pDCPD will attract increasing attention in the near future. ${ }^{241}$

\section{Conclusions}

In recent years, it became clear that pDCPD can compete effectively with epoxy- and polyester resins in many applications. Thanks to the intense research work conducted in the last two decades, environmentally robust initiators and the means to adjust the pot life of resins became available. With this achievement, the design freedom of creating resins was greatly enhanced. The use of many co-monomers or fillers unimaginable to employ with conventional initiators became feasible and new processing possibilities emerged. pDCPD based micro- and macroporous materials with intriguing mechanical properties became accessible. Silicareinforced nanocomposites emerged and fibre reinforced composites became accessible. The latter field of activity is of particular technological and economic interest and DCPD resins can now demonstrate their strengths. pDCPD is characterised by thermal and many mechanical properties which are comparable to competing resins but it shows a distinctly higher toughness. Its density is lower than that of many competing thermosets. DCPD-resins feature a low viscosity, allowing for faster and more flexible processing in consistently high quality. With the advent of new processing possibilities, such as frontal polymerisation or stereolithography, in the last few years, DCPD based resins offer another unique feature. Moreover, a company is advertising its DCPD technology with a considerably lower carbon footprint than epoxy resins. Although the underlying study for the claim has not been disclosed, the statement appears plausible.

Despite the tremendous discoveries and developments of the last decades, the authors are convinced that the real potential of pDCPD in materials chemistry is by far not uncovered.

\section{Conflicts of interest}

There are no conflicts to declare.

\section{Acknowledgements}

CS is indebted to the financial support through the Lead project LP-03 "Porous Materials@Work" of Graz University of Technology and SK acknowledges the financial support from the Slovenian Research Agency (grant P2-0145).

\section{Notes and references}

1 Register entry for DCPD at the European Chemical Agency see: https://echa.europa.eu/registration-dossier/-/registereddossier/15412.

2 T. T. P. Cheung, Cyclopentadiene and Dicyclopentadiene in KirkOthmer Encyclopedia of Chemical Technology, John Wiley \& Sons, 2001, DOI: 10.1002/0471238961.0325031211050514. a01.pub2.
3 D. Hönicke, R. Födisch, P. Claus and M. Olson, Cyclopendadiene and Cyclopentene in Ullmann's Encyclopedia of Industrial Chemistry, Wiley-VCH, 2012.

4 Market size estimations issued before the outbreak of the COVID-19 pandemic, https://marketersmedia.com/over-45cagr-dicyclopentadiene-market-size-will-bypass-800-millionby-2024/88898782 retrieved on April 13th, 2020.

5 A. Nickel and B. D. Edgecombe, Industrial Applications of ROMP in Polymer Science: A Comprehensive Reference, Elsevier, 2012, vol. 4, p. 749.

6 L. Matejka, C. Houtman and C. W. Macosko, Polymerization of Dicyclopentadiene: A New Reaction Injection Molding System, J. Appl. Polym. Sci., 1985, 30, 2787-2803.

7 J. C. Mol, Industrial applications of olefin metathesis, J. Mol. Catal. A: Chem., 2004, 213, 39-45.

8 C. Slugovc, in Industrial Applications of Olefin Metathesis Polymerization in Olefin Metathesis: Theory and Practice, ed. K. Grela, John Wiley \& Sons, 2014, pp. 329-334.

9 Z. Yao, L. W. Zhou, B.-B. Dai and K. Cao, Ring-opening metathesis copolymerization of dicyclopentadiene and cyclopentene through reaction injection molding process, J. Appl. Polym. Sci., 2012, 125, 2489-2493.

10 H.-G. Kim, H. J. Son, D.-K. Lee, D.-W. Kim, H. J. Park and D.-H. Cho, Optimization and analysis of reaction injection molding of polydicyclopentadiene using response surface methodology, Korean, J. Chem. Eng., 2017, 34, 2099-2109.

11 D. S. Breslow, Metathesis polymerization, Prog. Polym. Sci., 1993, 18, 1141-1195.

12 S. Monsaert, A. L. Vila, R. Drozdak, P. V. D. Voort and F. Verpoort, Latent olefin metathesis catalysts, Chem. Soc. Rev., 2009, 38, 3360-3372.

13 S. Naumann and M. R. Buchmeiser, Latent and delayed action polymerization systems, Macromol. Rapid Commun., 2014, 35, 682-701.

14 A. J. Teator, D. N. Lastovickova and C. W. Bielawski, Switchable Polymerization Catalysts, Chem. Rev., 2016, 116, 1969-1992.

15 A. J. Teator and C. W. Bielawski, Remote control Grubbs catalysts that modulate ring-opening metathesis polymerizations, J. Polym. Sci., Part A: Polym. Chem., 2017, 55, 2949-2960.

16 D. J. Nelson, S. Manzini, C. A. Urbina-Blanco and S. P. Nolan, Key processes in ruthenium-catalysed olefin metathesis, Chem. Commun., 2014, 50, 10355-10375.

17 C. Slugovc, S. Demel and F. Stelzer, Ring opening metathesis polymerisation in donor solvents, Chem. Commun., 2002, 2572-2573.

18 S. J. P'Poo and H.-J. Schanz, Reversible Inhibition/Activation of Olefin Metathesis: A Kinetic Investigation of ROMP and RCM Reactions with Grubb's Catalyst, J. Am. Chem. Soc., 2007, 129, 14200-14212.

19 M. R. Kessler and S. R. White, Cure kinetics of the ringopening metathesis polymerization of dicyclopentadiene, J. Polym. Sci., Part A: Polym. Chem., 2002, 40, 2373-2383.

20 X. Liu, X. Sheng, J. K. Lee and M. R. Kessler, Isothermal cure characterization of dicyclopentadiene, J. Therm. Anal. Calorim., 2007, 89, 453-457. 
21 G. Yang and J. K. Lee, Curing Kinetics and Mechanical Properties of endo-Dicyclopentadiene Synthesized Using Different Grubb's Catalysts, Ind. Eng. Chem. Res., 2014, 53, 3001-3011.

22 Y. Vidavsky, Y. Navon, Y. Ginzburg, M. Gottlieb and N. G. Lemcoff, Thermal properties of ruthenium alkylidenepolymerized dicyclopentadiene, Beilstein, J. Org. Chem., 2015, 11, 1469-1474.

23 A. Mariani, S. Fiori, Y. Chekanov and J. A. Pojman, Frontal Ring-Opening Metathesis Polymerization of Dicyclopentadiene, Macromolecules, 2001, 34, 6539-6541.

24 T. C. Mauldin and M. R. Kessler, Latent catalytic systems for ring-opening metathesis-based thermosets, J. Therm. Anal. Calorim., 2009, 96, 705-713.

25 H. M. Yoo, J. H. Jeon, M.-X. Li, W. I. Lee and S. W. Choi, Analysis of curing behavior of endo-dicyclopentadiene using different amounts of decelerator solution, Composites, Part B, 2019, 161, 439-454.

26 T. Weskamp, W. C. Schattenmann, M. Spiegler and W. A. Herrmann, A Novel Class of Ruthenium Catalysts for Olefin Metathesis, Angew. Chem., Int. Ed., 1998, 37, 2490-2493.

27 R. T. M. Jakobs and R. P. Sijbesma, Mechanical Activation of a Latent Olefin Metathesis Catalyst and Persistence of its Active Species in ROMP, Organometallics, 2012, 31, 2476-2481.

28 I. D. Robertson, L. M. Dean, G. E. Rudebusch, N. R. Sottos, S. R. White and J. S. Moore, Alkyl Phosphite Inhibitors for Frontal Ring-Opening Metathesis Polymerization Greatly Increase Pot Life, ACS Macro Lett., 2017, 6, 609-612.

29 A. Leitgeb, J. Wappel, C. A. Urbina-Blanco, S. Strasser, C. Wappl, C. S. J. Cazin and C. Slugovc, Two commercially available initiators for the retarded ring-opening metathesis polymerization of dicyclopentadiene, Monatsh. Chem., 2014, 145, 1513-1517.

30 X. Bantreil and C. S. J. Cazin, Phosphite ligands in Ru-based olefin metathesis catalysts, Monatsh. Chem., 2015, 146, 1043-1052.

31 B. Trzaskowski and K. Grela, Structural and Mechanistic Basis of the Fast Metathesis Initiation by a Six-Coordinated Ruthenium Catalyst, Organometallics, 2013, 32, 3625-3630.

32 Y. Vidavsky, A. Anabya and N. G. Lemcoff, Chelating alkylidene ligands as pacifiers for ruthenium catalysed olefin metathesis, Dalton Trans., 2012, 41, 32-43.

33 P. A. van der Schaaf, R. Kolly, H.-J. Kirner, F. Rime, A. Mühlebach and A. Hafner, Synthesis and reactivity of novel ruthenium carbene catalysts. X-ray structures of $\left[\mathrm{RuCl}_{2}\left(\mathrm{CHSC}_{6} \mathrm{H}_{5}\right)\left(\mathrm{P}^{\mathrm{i}} \mathrm{Pr}_{3}\right)_{2}\right]$ and $\left[\mathrm{RuCl}_{2}\left(\mathrm{CHCH}_{2} \mathrm{CH}_{2}-\mathrm{C}, \mathrm{N}-2-\right.\right.$ $\left.\left.\mathrm{C}_{5} \mathrm{H}_{4} \mathrm{~N}\right)\left(\mathrm{P}^{\mathrm{i}} \mathrm{Pr}_{3}\right)\right]$, J. Organomet. Chem., 2000, 606, 65-74.

34 T. Ung, A. Hejl, R. H. Grubbs and Y. Schrodi, Latent Ruthenium Olefin Metathesis Catalysts That Contain an N-Heterocyclic Carbene Ligand, Organometallics, 2004, 23, 5399-5401.

35 N. M. Shcheglova, V. D. Kolesnik, R. V. Ashirov and E. A. Krasnokutskaya, Latent ruthenium carbene complexes with six-membered $\mathrm{N}$ - and S-chelate rings, Russ. Chem. Bull., 2016, 65, 490-497.
36 A. A. Lyapkov, L. S. Soroka, R. V. Ashirov, D. I. Zemlyakov, D. A. Rusakov and F. Verpoort, Kinetics of Dicyclopentadiene Polymerization in the Presence of the Second Generation Hoveyda-Grubbs Catalyst with N-Chelating Ligand, Polym. Sci. C, 2019, 61, 41-48.

37 V. V. Afanas'ev, T. M. Yumasheva and N. B. Bespalova, Promising Catalytic Processes of Dicyclopentadiene Metathesis Polymerization to Obtain a New Class of Polymeric and Polymer-Composite Materials, Polym. Sci. C, 2019, 61, 31-40.

38 D. Sivanesan, B. Seo, C.-S. Lim, D. Choi, T. Kima and H.-G. Kim, An additional potential donor-bearing alkylidenecontaining latent NHC-ruthenium-based catalyst for olefin metathesis polymerization, Polym. Chem., 2020, 11, 2511-2518.

39 Y. Ginzburg, A. Anaby, Y. Vidavsky, C. E. Diesendruck, A. Ben-Asuly, I. Goldberg and N. G. Lemcoff, Widening the Latency Gap in Chelated Ruthenium Olefin Metathesis Catalysts, Organometallics, 2011, 30, 3430-3437.

40 A. Hejl, M. W. Day and R. H. Grubbs, Latent Olefin Metathesis Catalysts Featuring Chelating Alkylidenes, Organometallics, 2006, 25, 6149-6154.

41 E. Pump, A. Leitgeb, A. Kozłowska, A. Torvisco, L. Falivene, L. Cavallo, K. Grela and C. Slugovc, Variation of the Sterical Properties of the N-Heterocyclic Carbene Coligand in Thermally Triggerable Ruthenium-Based Olefin Metathesis Precatalysts/Initiators, Organometallics, 2015, 34, 5383-5392.

42 S. J. Czarnocki, I. Czeluśniak, T. K. Olszewski, M. Malinska, K. Woźniak and K. Grela, Rational and Then Serendipitous Formation of Aza Analogues of Hoveyda-Type Catalysts Containing a Chelating Ester Group Leading to a Polymerization Catalyst Family, ACS Catal., 2017, 7, 4115-4121.

43 B. Allaert, N. Dieltiens, N. Ledoux, C. Vercaemst, P. Van Der Voort, C. V. Stevens, A. Linden and F. Verpoort, Synthesis and activity for ROMP of bidentate Schiff base substituted second generation Grubbs catalysts, J. Mol. Catal. A: Chem., 2006, 260, 221-226.

44 S. Monsaert, N. Ledoux, R. Drozdzak and F. Verpoort, A highly controllable latent ruthenium Schiff base olefin metathesis catalyst: Catalyst activation and mechanistic studies, J. Polym. Sci., Part A: Polym. Chem., 2010, 48, 302-310.

45 J. S. M. Samec, B. K. Keitz and R. H. Grubbs, Latent ruthenium olefin metathesis catalysts featuring a phosphine or an N-heterocyclic carbene ligand, J. Organomet. Chem., 2010, 695, 1831-1837.

46 J. Wappel, R. C. Fischer, L. Cavallo, C. Slugovc and A. Poater, Simple activation by acid of latent Ru-NHC-based metathesis initiators bearing 8-quinolinolate co-ligands, Beilstein J. Org. Chem., 2016, 12, 154-165.

47 R. Gawin, A. Makal, K. Woźniak, M. Mauduit and K. Grela, A dormant ruthenium catalyst bearing a chelating carboxylate ligand: in situ activation and application in metathesis reactions, Angew. Chem., Int. Ed., 2007, 46, 7206-7209.

48 A. Kozłowska, M. Dranka, J. Zachara, E. Pump, C. Slugovc, K. Skowerski and K. Grela, Chelating Ruthenium Phenolate 
Complexes-Synthesis, General Catalytic Activity and Applications in Olefin Metathesis Polymerisation, Chem. - Eur. J., 2014, 20, 14120-14125.

49 A. Gawin, E. Pump, C. Slugove, A. Kajetanowicz and K. Grela, Ruthenium-amide Complexes - Synthesis and Catalytic Activity in Olefin Metathesis and in Ring Opening Polymerization, Eur. J. Inorg. Chem., 2018, 1766-1774.

50 J. Beerhues, S. Sen, R. Schowner, G. M. Nagy, D. Wang and M. R. Buchmeiser, Tailored molybdenum imido alkylidene $\mathrm{N}$-heterocyclic carbene complexes as latent catalysts for the polymerization of dicyclopentadiene, J. Polym. Sci., Part A: Polym. Chem., 2017, 55, 3028-3033.

51 I. Elser, B. R. Kordes, W. Frey, K. Herz, R. Schowner, L. Stöhr, H. J. Altmann and M. R. Buchmeiser, Latent and Air-Stable Pre-Catalysts for the Polymerization of Dicyclopentadiene: From Penta- to Hexacoordination in Molybdenum Imido Alkylidene N-Heterocyclic Carbene Complexes, Chem. - Eur. J., 2018, 24, 12652-12659.

52 L. Ondi, G. M. Nagy, J. B. Czirok, A. Bucsai and G. E. Frater, From Box to Bench: Air-Stable Molybdenum Catalyst Tablets for Everyday Use in Olefin Metathesis, Org. Process Res. Dev., 2016, 20, 1709-1716.

53 T. Ritter, A. Hejl, A. G. Wenzel, T. W. Funk and R. H. Grubbs, A Standard System of Characterization for Olefin Metathesis Catalysts, Organometallics, 2006, 25, 5740-5745.

54 S. L. Balof, K. O. Nix, M. S. Olliff, S. E. Roessler, A. Saha, K. B. Müller, U. Behrens, E. J. Valente and H.-J. Schanz, Hexacoordinate Ru-based olefin metathesis catalysts with $\mathrm{pH}$ responsive $\mathrm{N}$-heterocyclic carbene (NHC) and $\mathrm{N}$-donor ligands for ROMP reactions in non-aqueous, aqueous and emulsion conditions, Beilstein J. Org. Chem., 2015, 11, 1960-1972.

55 O. Eivgi and N. G. Lemcoff, Turning the Light On: Recent Developments in Photoinduced Olefin Metathesis, Synthesis, 2018, 49-63.

56 T. Karlen, A. Ludi, A. Mühlebach, P. Bernhard and C. Pharisa, Photoinduced ring opening metathesis polymerization (PROMP) of strained bicyclic olefins with ruthenium complexes of the type $\left[(\eta 6 \text {-arene } 1) \mathrm{Ru}\left(\eta^{6} \text {-arene } 2\right)\right]^{2+}$ and $\left[\mathrm{Ru}(\mathrm{Nc}-\mathrm{R})_{6}\right]^{2+}$,J. Polym. Sci., Part A: Polym. Chem., 1995, 33, 1665-1674.

57 A. Hafner, A. Mühlebach and P. A. van der Schaaf, OneComponent Catalysts for Thermal and Photoinduced Ring Opening Metathesis Polymerization, Angew. Chem., Int. Ed. Engl., 1997, 36, 2121-2124.

58 D. Wang, K. Wurst, W. Knolle, U. Decker, L. Prager, S. Naumov and M. R. Buchmeiser, Cationic $\mathrm{Ru}^{\mathrm{II}}$ Complexes with N-Heterocyclic Carbene Ligands for UV-Induced RingOpening Metathesis Polymerization, Angew. Chem., Int. Ed., 2008, 47, 3267-3270.

59 D. Wang, K. Wurst and M. R. Buchmeiser, Cationic versus Neutral Ru ${ }^{\mathrm{II}} \mathrm{N}-\mathrm{Heterocyclic}$ Carbene Complexes as Latent Precatalysts for the UV-Induced Ring-Opening Metathesis Polymerization, Chem. - Eur. J., 2010, 16, 12928-12934.

60 J. Pinaud, T. K. H. Trinh, D. Sauvanier, E. Placet, S. Songsee, P. Lacroix-Desmazes, J.-M. Becht, B. Tarablsi, J. Lalevée, L. Pichavant, V. Héroguez and A. Chemtob,
In Situ Generated Ruthenium-Arene Catalyst for Photoactivated Ring-Opening Metathesis Polymerization through Photolatent N-Heterocyclic Carbene Ligand, Chem. - Eur. J., 2018, 24, 337-341.

61 T. K. H. Trinh, G. Schrodj, S. Rigolet, J. Pinaud, P. LacroixDesmazes, L. Pichavant, V. Héroguez and A. Chemtob, Combining a ligand photogenerator and a Ru precatalyst: a photoinduced approach to cross-linked ROMP polymer films, RSC Adv., 2019, 9, 27789-27799.

62 D. Wang, J. Unold, M. Bubrin, I. Elser, W. Frey, W. Kaim, G. Xu and M. R. Buchmeiser, Ruthenium-Triazene Complexes as Latent Catalysts for UV-Induced ROMP, Eur. J. Inorg. Chem., 2013, 5462-5468.

63 O. Eivgi, S. Guidone, A. Frenklah, S. Kozuch, I. Goldberg and N. G. Lemcoff, Photoactivation of Ruthenium Phosphite Complexes for Olefin Metathesis, ACS Catal., 2018, 8, 6413-6418.

64 O. Eivgi, A. Vaisman, N. B. Nechmad, M. Baranov and N. G. Lemcoff, Latent Ruthenium Benzylidene Phosphite Complexes for Visible-Light-Induced Olefin Metathesis, ACS Catal., 2020, 10, 2033-2038.

65 C. Theunissen, M. A. Ashley and T. Rovis, Visible-LightControlled Ruthenium-Catalyzed Olefin Metathesis, J. Am. Chem. Soc., 2019, 141, 6791-6796.

66 A. Goetz and A. J. Boydston, Metal-Free Preparation of Linear and Cross-Linked Polydicyclopentadiene, J. Am. Chem. Soc., 2015, 137, 7572-7575.

67 B. K. Keitz and R. H. Grubbs, A Tandem Approach to Photoactivated Olefin Metathesis: Combining a Photoacid Generator with an Acid Activated Catalyst, J. Am. Chem. Soc., 2009, 131, 2038-2039.

68 W. Joo, C. H. Chen, J. P. Moerdyk, R. P. Deschner, C. W. Bielawski and C. G. Willson, Photoinitiated ringopening metathesis polymerization, J. Polym. Sci., Part A: Polym. Chem., 2019, 57, 1791-1795.

69 C. W. Bielawski and R. H. Grubbs, Living ring-opening metathesis polymerization, Prog. Polym. Sci., 2007, 32, 1-29.

70 I. Njoroge, P. A. Kempler, X. Deng, S. T. Arnold and G. K. Jennings, Surface-Initiated Ring-Opening Metathesis Polymerization of Dicyclopentadiene from the Vapor Phase, Langmuir, 2017, 33, 13903-13912.

71 G. Yang and J. K. Lee, Curing Kinetics and Mechanical Properties of endo-Dicyclopentadiene Synthesized Using Different Grubb's Catalysts, Ind. Eng. Chem. Res., 2014, 53, 3001-3011.

72 J. D. Rule and J. S. Moore, ROMP reactivity of endo- and exodicyclopentadiene, Macromolecules, 2002, 35, 7878-7882.

73 R. A. Fisher and R. H. Grubbs, Ring-opening metathesis polymerization of exo-dicyclopentadiene: reversible crosslinking by a metathesis catalyst, Macromol. Chem. Macromol. Symp., 1992, 63, 271-277.

74 T. A. Davidson, K. B. Wagener and D. B. Priddy, Polymerization of Dicyclopentadiene: A Tale of Two Mechanisms, Macromolecules, 1996, 29, 786-788.

75 T. A. Davidson and K. B. Wagener, The polymerization of dicyclopentadiene: an investigation of mechanism, J. Mol. Catal. A: Chem., 1998, 133, 67-74. 
76 D. Dimonie, M. Dimonie, V. Munteanu, H. Iovu, J. Couve and M. J. Abadie, Nature of the first exothermic peak on the DSC curve of linear polydicyclopentadiene obtained with a special catalytic system, Polym. Degrad. Stab., 2000, 70, 319-324.

77 D. Dimonie, M. Dimonie, S. Stoica, V. Munteanu and M. J. Abadie, Some aspects of the thermal stability of linear polydicyclopentadiene (L-PDCPD), Polym. Degrad. Stab., 2000, 67, 167-170.

78 P. Y. Le Gac, D. Choqueuse, M. Paris, G. Recher, C. Zimmer and D. Melot, Durability of polydicyclopentadiene under high temperature, high pressure and seawater (Offshore Oil Production Conditions), Polym. Degrad. Stab., 2013, 98, 809-817.

79 S. Bhuyan, S. Sundararajan, X. Sheng and M. Kessler, Influence of crosslinking density on the tribological behaviour of norbornene-based polymeric materials, Wear, 2011, 270, 550-554.

80 X. Sheng, J. K. Lee and M. R. Kessler, Influence of crosslink density on the properties of ROMP thermosets, Polymer, 2009, 50, 1264-1269.

81 T. R. Long, R. M. Elder, E. D. Bain, K. A. Masser, T. W. Sirk, J. H. Yu, D. B. Knorr, Jr. and J. L. Lenhart, Influence of molecular weight between crosslinks on the mechanical properties of polymers formed via ring-opening metathesis, Soft Matter, 2018, 14, 3344-3360.

82 V. J. Toplosky and R. P. Walsh, Thermal and Mechanical Properties of Poly-Dicyclopentadiene (DCPD) at Cryogenic Temperatures, AIP Conf. Proc., 2006, 824, 219-224.

83 R. M. Elder, D. B. Knorr Jr, J. W. Andzelm, J. L. Lenhart and T. W. Sirk, Nanovoid formation and mechanics: a comparison of poly(dicyclopentadiene) and epoxy networks from molecular dynamics simulations, Soft Matter, 2016, 12, 4418-4434.

84 R. M. Elder, A. Zaccone and T. W. Sirk, Identifying Nonaffine Softening Modes in Glassy Polymer Networks: A Pathway to Chemical Design, ACS Macro Lett., 2019, 8, 1160-1165.

85 D. B. Knorr Jr, K. A. Masser, R. M. Elder, T. W. Sirk, M. D. Hindenlang, J. H. Yu, A. D. Richardson, S. E. Boyd, W. A. Spurgeon and J. L. Lenhart, Overcoming the structural versus energy dissipation trade-off in highly crosslinked polymer networks: Ultrahigh strain rate response in polydicyclopentadiene, Compos. Sci. Technol., 2015, 114, 17-25.

86 A. Bang, D. Mohite, A. M. Saeed, N. Leventis and C. SotiriouLeventis, Polydicyclopentadiene Aerogels from First- versus Second-Generation Grubb's Catalysts: A Molecular versus a Nanoscopic Perspective, J. Sol-Gel Sci. Technol., 2015, 75, 460-474.

87 S. Hayano, T. Sugawara and Y. Tsunogae, Synthesis, characterization, and properties of crystalline poly(endodicyclopentadiene) resin made via cis- and isoselective bulk ring-opening metathesis polymerization, J. Polym. Sci., Part A: Polym. Chem., 2006, 44, 3153-3158.

88 S. Hayano, Y. Takeyama, Y. Tsunogae and I. Igarashi, Hydrogenated Ring-Opened Poly(endo-dicyclopentadiene)s
Made via Stereoselective ROMP Catalyzed by Tungsten Complexes: Crystalline Tactic Polymers and Amorphous Atactic Polymer, Macromolecules, 2006, 39, 4663-4670.

89 B. Autenrieth, H. Jeong, W. P. Forrest, J. C. Axtell, A. Ota, T. Lehr, M. R. Buchmeiser and R. R. Schrock, Stereospecific Ring-Opening Metathesis Polymerization (ROMP) of endo-Dicyclopentadiene by Molybdenum and Tungsten Catalysts, Macromolecules, 2015, 48, 2480-2492.

90 A. Mühlebach, P. A. van der Schaaf, A. Hafner and F. Setiabudi, Thermal stability and degradation of hydrocarbon metathesis polymers, J. Mol. Catal. A: Chem., 1998, 132, 181-188.

91 V. Defauchy, P.-Y. Le Gac, A. Guinault, J. Verdu, G. Recher, R. Drozdzak and E. Richaud, Kinetic analysis polydicyclopentadiene oxidation, Polym. Degrad. Stab., 2017, 142, 169-177.

92 J. Huang, W. Minne, R. Drozdzak, G. Recher, P.-Y. Le Gac and E. Richaud, Thermal oxidation of poly(Dicyclopentadiene)Decomposition of Hydroperoxides, Polym. Degrad. Stab., 2020, 174, 109102.

93 E. Richaud, P. Y. Le Gac and J. Verdu, Thermooxidative aging of polydicyclopentadiene in glassy state, Polym. Degrad. Stab., 2014, 102, 95-104.

94 J. Huang, A. David, P.-Y. Le Gac, C. Lorthioir, C. Coelho and E. Richaud, Thermal oxidation of poly(dicyclopentadiene)kinetic modeling of double bond consumption, Polym. Degrad. Stab., 2019, 166, 258-271.

95 B. Wang, K. Mireles, M. Rock, Y. Li, V. K. Thakur, D. Gao and M. R. Kessler, Synthesis and Preparation of Bio-Based ROMP Thermosets from Functionalized Renewable Isosorbide Derivative, Macromol. Chem. Phys., 2016, 217, 871-879.

96 R. Ding, Y. Xia, T. C. Mauldin and M. R. Kessler, Biorenewable ROMP-based thermosetting copolymers from functionalized castor oil derivative with various cross-linking agents, Polymer, 2014, 55, 5718-5726.

97 H. Cui and M. R. Kessler, Composition-dependent fracture toughness of ROMP-based Dilulin/dicyclopentadiene copolymers, J. Mater. Sci., 2014, 49, 4880-4890.

98 R. T. Mathers, K. Damodaran, M. G. Rendos and M. S. Lavrich, Functional Hyperbranched Polymers Using Ring-Opening Metathesis Polymerization of Dicyclopentadiene with Monoterpenes, Macromolecules, 2009, 42, 1512-1518.

99 J. M. Delancey, M. D. Cavazza, M. G. Rendos, C. J. Ulisse, S. G. Palumbo and R. T. Mathers, Controlling crosslinking in thermosets via chain transfer with monoterpenes, J. Polym. Sci., Part A: Polym. Chem., 2011, 49, 3719-3727.

100 E. M. Hensle and S. A. Blum, Phase Separation Polymerization of Dicyclopentadiene Characterized by In Operando Fluorescence Microscopy, J. Am. Chem. Soc., 2013, 135, 12324-12328.

101 F. Hu, Y. Zheng, Y. Fang, X. Ren and X. Liu, Preparation and properties of cyclopentadiene-containing monomer modified polydicyclopentadiene, Polymer, 2014, 55, 2809.

102 F. Hu, Y. Zheng, Y. Fang, X. Ren and X. Liu, Preparation and properties of high performance phthalide - containing bismaleimide reinforced polydicyclopentadiene, J. Appl. Polym. Sci., 2014, 131, 40474. 
103 J. Kuang, N. Zheng, C. Liu and Y. Zheng, Manipulating the thermal and dynamic mechanical properties of polydicyclopentadiene via tuning the stiffness of the incorporated monomers, e-Polymers, 2019, 19, 355-364.

104 B. J. Rohde, M. L. Robertson and R. Krishnamoorti, Concurrent curing kinetics of an anhydride-cured epoxy resin and polydicyclopentadiene, Polymer, 2015, 69, 204-214.

105 B. J. Rohde, K. M. Le, R. Krishnamoorti and M. L. Robertson, Thermoset Blends of an Epoxy Resin and Polydicyclopentadiene, Macromolecules, 2016, 49, 8960-8970.

106 M. Liu, B. J. Rohde, R. Krishnamoorti, M. L. Robertson and M. Dawood, Bond behavior of epoxy resin-polydicyclopentadiene phase separated interpenetrating networks for adhering carbon fiber reinforced polymer to steel, Polym. Eng. Sci., 2020, 60, 104-112.

107 B. Pan, J. Du, C. Zhang, S. Du, J. Zhang, J. Liu, Y. Zhang and Y. Zhang, Reinforcing effect of low polyethylene wax content on polydicyclopendadiene, J. Macromol. Sci., Part B: Phys., 2014, 53, 440-451.

108 G. S. Constable, A. J. Lesser and E. B. Coughlin, Morphological and Mechanical Evaluation of Hybrid Organic-Inorganic Thermoset Copolymers of Dicyclopentadiene and Monoor Tris(norbornenyl)-Substituted Polyhedral Oligomeric Silsesquioxanes, Macromolecules, 2004, 37, 1276-1282.

109 Y. Wang, L. Zhang, J. Sun, J.-B. Bao, Z. Wang and L. Ni, Dramatic Toughness Enhancement of Polydicyclopentadiene Composites by Incorporating Low Amounts of VinylFunctionalized $\mathrm{SiO}_{2}$, Ind. Eng. Chem. Res., 2017, 56, 4750-4757.

110 Z.-L. He, J.-K. Xu, L. Zhang, H.-Y. Ren and S.-Y. Fu, Dramatically enhanced tensile strength and impact toughness of polydicyclopentadiene composites by covalent bond formation between phenyl-functionalized silica and dicyclopentadiene, Composites, Part B, 2019, 170, 31-40.

111 H.-Y. Ren, Z.-L. He, D.-L. Li, L. Zhang, L.-N. Chen, Y.-W. Lou and M.-D. Xu, Synergistic enhanced yield strength, tensile ductility and impact toughness of polydicyclopentadiene nanocomposites by introducing low loadings of di-functionalized silica, Polym. Test., 2019, 79, 106052.

112 Z.-L. He, L.-N. Chen, L. Zhang, H.-Y. Ren, M.-D. Xu and Y.-W. Lou, Effect of filler functional groups on the mechanical properties and relevant mechanisms of polydicyclopentadiene nanocomposites, J. Appl. Polym. Sci., 2020, 49010.

113 S. Peng, K. Chang, J. Ma, B. Pan, J. Zhang and Q. Niu, In-situ polymerization of silica/polydicyclopentadiene nanocomposites: Improved tribological properties and evaluation of interfacial compatibility, Ferroelectrics, 2018, 523, 22-31.

114 S. Peng, K. Chang, J. Ma, B. Pan, J. Zhang and Q. Niu, Silica/ polydicyclopentadiene nanocomposites: Preparation, characterization, and mechanical properties, Ferroelectrics, 2018, 523, 32-40.

115 B. Pan, Y. Cheng, Y. Wang, Y. Feng, W. Ye, Y. Tian and X. Wang, Polydicyclopentadiene Reinforced with Grafted Silica Nanoparticles, Polym.-Plast. Technol. Eng., 2013, 52, 586-591.

116 S. G. Peng, Y. P. Niu and X. J. Fan, Enhancement of Mechanical and Tribological Properties in Ring-Opening
Metathesis Polymerization Functionalized Molybdenum Disulfide/Polydicyclopentadiene Nanocomposites, J. Appl. Polym. Sci., 2013, 129, 1045-1052.

117 W. Yin, S. Kniajanski and B. Amm, Dielectric properties of polydicyclopentadiene and polydicyclopentadiene-silica nanocomposite, IEEE Int. Symp. Electr. Insul., San Diego, CA, 2010, pp. 1-5.

118 P. Culver, C. W. Beier, J. P. Rafson and R. L. Brutchey, Surface modification of $\mathrm{BaTiO}_{3}$ inclusions in polydicyclopentadiene nanocomposites for energy storage, J. Appl. Polym. Sci., 2014, 131, 40290.

119 M. Yoonessi, H. Toghiani, W. L. Kingery and C. U. Pittman, Preparation characterization and properties of exfoliated/delaminated organically modified clay/dicyclopentadiene resin nanocomposites, Macromolecules, 2004, 37, 10365-10371.

120 M. Yoonessi, H. Toghiani, T. L. Daulton, J.-S. Lin and C. U. Pittman, Clay Delamination in Clay/Poly(Dicyclopentadiene) Nanocomposites Quantified by Small Angle Neutron Scattering and High-Resolution Transmission Electron Microscopy, Macromolecules, 2005, 38, 818-831.

121 B. L. Pan, Y. L. Xing, C. F. Zhang and Y. Q. Zhang, Study on Erosion Wear Behavior of PDCPD/MMT Nanocomposite, Adv. Mater. Res., 2010, 123, 231-234.

122 Y. X. He, Y. N. Yan, L. Zhang, S. B. Zhu and Y. Q. Zhang, Preparation and Properties of Polydicyclopentadiene/MMt Nanocomposites Using Supported Tungsten Catalyst, Polym.-Plast. Technol. Eng., 2011, 50, 1103-1108.

123 R. Simons, S. N. Guntari, T. K. Goh, G. G. Qiao and S. A. Bateman, Poly(dicyclopentadiene)-montmorillonite nanocomposite formation via simultaneous intergallerysurface initiation and chain crosslinking using ROMP, J. Polym. Sci., Part A: Polym. Chem., 2012, 50, 89-97.

124 W. Jeong and M. R. Kessler, Toughness Enhancement in ROMP Functionalized Carbon Nanotube/Polydicyclopentadiene Composites, Chem. Mater., 2008, 22, 7060-7068.

125 G. Yang, S. C. Lee and J. K. Lee, Reinforcement of norbornene-based nanocomposites with norbornene functionalized multi-walled carbon nanotubes, Chem. Eng. J., 2016, 288, 9-18.

126 Z. He, J. Sun, L. Zhang, Y. Wang, H. Ren and J.-B. Bao, Synergistic reinforcing and toughening of polydicyclopentadiene nanocomposites with low loadings vinylfunctionalized multi-walled carbon nanotubes, Polymer, 2018, 153, 287-294.

127 B. L. Pan, C. F. Zhang, J. Zhao, Y. Q. Zhang and Y. Z. Zhang, Mechanical properties of polydicyclopentadiene/graphite nanosheet composites prepared by reaction injection moulding, Plast., Rubber Compos., 2012, 41, 319-325.

128 F. Y. Hu, J. Du and Y. B. Zheng, Morphological effect of fillers on graphite reinforced polydicyclopentadiene based composites, Polym. Compos., 2014, 35, 1918-1925.

129 F. Y. Hu, J. Du, Y. Fang, X. Ren, X. Liu and Y. B. Zheng, In situ formation of mildly oxidized graphene oxid/polydicyclopentadiene composite and reinforced mechanical and thermal performances, J. Macromol. Sci., 2014, $\mathbf{5 1 ,} 3246$. 
130 J. H. Jeon, W. I. Lee, J. M. Choi and S. W. Choi, Analysis of Cryogenic Impact Properties for a Glass-Fiber-Reinforced Dicyclopentadiene with a Different Amount of Decelerator Solution, Materials, 2019, 12, 439-454.

131 K. A. M. Vallons, R. Drozdzak, M. Charret, S. V. Lomov and I. Verpoest, Assessment of the mechanical behaviour of glass fibre composites with a tough polydicyclopentadiene (PDCPD) matrix, Composites, Part A, 2015, 78, 191-200.

132 J.-H. Kim, D.-J. Kwon, P.-S. Shin, H.-S. Park, Y.-M. Baek, K. L. DeVries and J.-M. Park, Evaluation of interfacial and mechanical properties of glass fiber and p-DCPD composites with surface treatment of glass fiber, Composites, Part B, 2018, 153, 420-428.

133 H. Cui and M. R. Kessler, Glass fiber reinforced ROMPbased bio-renewable polymers: Enhancement of the interface with silane coupling agents, Compos. Sci. Technol., 2012, 72, 1264-1272.

134 H. M. Yoo, D. J. Kwon, J. M. Park, S. H. Yum and W. I. Lee, Mechanical properties of norbornene-based silane treated glass fiber reinforced polydicyclopentadiene composites manufactured by the S-RIM process, e-Polymers, 2017, 17, 159-166.

135 Y. Hu, A. W. Lang, X. Li and S. R. Nutt, Hygrothermal aging effects on fatigue of glass fiber/polydicyclopentadiene composites, Polym. Degrad. Stab., 2014, 110, 464-472.

136 Y. Hu, X. Li, A. W. Lang, Y. Zhang and S. R. Nutt, Water immersion aging of polydicyclopentadiene resin and glass fiber composites, Polym. Degrad. Stab., 2016, 124, 35-42.

137 Y. Hu, Y. Zhang and S. Nutt, Thermal oxidation aging of polydicyclopentadiene and composites, Polym. Compos., 2018, 39, 1742-1751.

138 E. Devaux, C. Caze, G. Recher and D. Bielarski, Characterization of interfacial adhesion in a ultra-high-molecularweight polyethylene reinforced polydicyclopentadiene composite, Polym. Test., 2002, 21, 457-462.

139 H. M. Yoo, M. S. Kim, B. S. Kim, D. J. Kwon and S. W. Choi, Impact and shear properties of carbon fabric/poly-dicyclopentadiene composites manufactured by vacuum-assisted resin transfer molding, e-Polymers, 2019, 19, 437-443.

140 W. Xin, J. Severino, A. Venkert, H. Yu, D. Knorr, J.-M. Yang, L. Carlson, R. Hicks and I. De Rosa, Fabrication and Characterization of Solid Composite Yarns from Carbon Nanotubes and Poly(dicyclopentadiene), Nanomaterials, 2020, 10, 717.

141 H. A. Colorado, W. Yuan, Z. Guo, J. Juanri and J.-M. Yang, Poly-dicyclopentadiene-wollastonite composites toward structural applications, J. Compos. Mater., 2014, 48, 2023-2031.

142 Z. Chen and S. S. Zhu, In-situ polymerization of dicyclopentadiene for rock reinforcement, J. Pet. Sci. Eng., 2019, 173, 912-921.

143 D. G. Bekas, K. Tsirka, D. Baltzis and A. S. Paipetis, Selfhealing Materials: A Review of Advances in Materials, Evaluation, Characterization, and Monitoring Techniques, Composites, Part B, 2016, 87, 92-119.

144 S. R. White, N. R. Sottos, P. H. Geubelle, J. S. Moore, M. R. Kessler, S. R. Sriram, E. N. Brown and S. Viswanathan,
Autonomic healing of polymer composites, Nature, 2001, 409, 794-797.

145 G. O. Wilson, J. S. Moore, S. R. White, N. R. Sottos and H. M. Andersson, Autonomic Healing of Epoxy Vinyl Esters via Ring Opening Metathesis Polymerization, Adv. Funct. Mater., 2008, 18, 44-52.

146 E. N. Brown, N. R. Sottos and S. R. White, Fracture testing of a self-healing polymer composite, Exp. Mech., 2002, 42, 372-379.

147 M. R. Kessler, N. R. Sottos and S. R. White, Self-healing structural composite materials, Composites, Part A, 2003, 34, 743-753.

148 E. N. Brown, S. R. White and N. R. Sottos, Retardation and repair of fatigue cracks in a microcapsule toughened epoxy composite-Part I: Manual infiltration, Compos. Sci. Technol., 2005, 65, 2466-2473.

149 E. N. Brown, S. R. White and N. R. Sottos, Retardation and repair of fatigue cracks in a microcapsule toughened epoxy composite-Part II: In situ self-healing, Compos. Sci. Technol., 2005, 65, 2474-2480.

150 D. Rule, E. N. Brown, N. R. Sottos, S. R. White and J. S. Moore, Wax-Protected Catalyst Microspheres for Efficient Self-Healing Materials, Adv. Mater., 2005, 17, 205-208.

151 J. D. Rule, N. R. Sottos and S. R. White, Effect of microcapsule size on the performance of self-healing polymers, Polymer, 2007, 48, 3520-3529.

152 G. O. Wilson, M. M. Caruso, N. T. Reimer, S. R. White, N. R. Sottos and J. S. Moore, Evaluation of Ruthenium Catalysts for Ring-Opening Metathesis PolymerizationBased Self-Healing Applications, Chem. Mater., 2008, 20, 3288-3297.

153 L. Guadagno, P. Longo, M. Raimondo, C. Naddeo, A. Mariconda, V. Vittoria, G. Iannuzzo and S. Russo, Use of Hoveyda-Grubb's second generation catalyst in self-healing epoxy mixtures, Composites, Part B, 2011, 42, 296-301.

154 B. Özgün, Ö. Solmaz and K. Şehitoğlu, Applications of ruthenium indenylidene catalysts on ROMP-based selfhealing epoxy systems, Polymer, 2015, 69, 343-348.

155 L. Guadagno, A. Mariconda, A. Agovino, M. Raimondo and P. Longo, Protection of graphene supported ROMP catalyst through polymeric globular shell in self-healing materials, Composites, Part B, 2017, 116, 352-360.

156 P. Longo, A. Mariconda, E. Calabrese, M. Raimondo, C. Naddeo, L. Vertuccio, S. Russo, G. Iannuzzo and L. Guadagno, Development of a new stable ruthenium initiator suitably designed for self-repairing applications in high reactive environments, Ind. Eng. Chem. Res., 2017, 54, 234-251.

157 K. S. Toohey, N. R. Sottos, J. A. Lewis, J. S. Moore and S. R. White, Self-Healing Materials With Microvascular Networks, Nat. Mater., 2007, 6, 581-585.

158 R. Shen, R. S. Amano, G. Lewinski, A. Kumar and K. Matt, A New Vascular System Highly Efficient in the Storage and Transport of Healing Agent for Self-Healing Wind Turbine Blades, J. Energy Resour. Technol., 2019, 141, 051212.

159 R. Shen, R. S. Amano and G. Lewinski, Self-Healing Performance Comparison Between Two Promising Vascular 
Vessel Systems of the Wind Turbine Blade, J. Energy Resour. Technol., 2019, 141, 111203.

160 A. Ruiu, D. Sanna, V. Alzari, D. Nuvoli and A. Mariani, Advances in the frontal ring opening metathesis polymerization of dicyclopentadiene, J. Polym. Sci., Part A: Polym. Chem., 2014, 52, 2776-2780.

161 V. Alzari, D. Nuvoli, D. Sanna, A. Ruiu and A. Mariani, Effects of limonene on the frontal ring opening metathesis polymerization of dicyclopentadiene, J. Polym. Sci., Part A: Polym. Chem., 2016, 54, 63-68.

162 I. D. Robertson, E. L. Pruitt and J. S. Moore, Frontal RingOpening Metathesis Polymerization of Exo-Dicyclopentadiene for Low Catalyst Loadings, ACS Macro Lett., 2016, 5, 593-596.

163 I. D. Robertson, M. Yourdkhani, P. J. Centellas, J. E. Aw, D. G. Ivanoff, E. Goli, E. M. Lloyd, L. M. Dean, N. R. Sottos, P. H. Geubelle, J. S. Moore and S. R. White, Rapid EnergyEfficient Manufacturing of Polymers and Composites via Frontal Polymerization, Nature, 2018, 557, 223-227.

164 E. Goli, I. D. Robertson, P. H. Geubelle and J. S. Moore, Frontal Polymerization of Dicyclopentadiene: A Numerical Study, J. Phys. Chem. B, 2018, 122, 4583-4591.

165 H. Liu, H. Wei and J. S. Moore, Frontal Ring-Opening Metathesis Copolymerization: Deviation of Front Velocity from Mixing Rules, ACS Macro Lett., 2019, 8, 846-851.

166 B. Wang, K. F. Arias, Z. Zhang, Y. Liu, Z. Jiang, H.-J. Sue, N. Currie-Gregg, S. Bouslog, Z. J. Pei and S. Wang, 3D printing of in-situ curing thermally insulated thermosets, Manuf. Lett., 2019, 21, 1-6.

167 L. M. Bellan, G. W. Coates and H. G. Craighead, Poly(dicyclopentadiene) submicron fibers produced by electrospinning, Macromol. Rapid Commun., 2006, 27, 511-515.

168 D. Fu, L.-T. Weng, B. Du, O. K. C. Tsui and B. Xu, Solventless Polymerization at the Gas-Solid Interface to Form Polymeric Thin Films, Adv. Mater., 2002, 14, 339-343.

169 H. T. Ban, M. Shigeta, T. Nagamune and M. Uejima, Synthesis of cyclo-olefin copolymer latexes and their carbon nanotube composite nanoparticles, J. Polym. Sci., Part A: Polym. Chem., 2013, 51, 4584-4591.

170 J. N. Talbert, L.-S. Wang, B. Duncan, Y. Jeong, S. M. Andler, V. M. Rotello and J. M. Goddard, Immobilization and Stabilization of Lipase (CaLB) through Hierarchical Interfacial Assembly, Biomacromolecules, 2014, 15, 3915-3922.

171 S. M. Andler, L.-S. Wang, J. M. Goddard and V. M. Rotello, Preparation of Biocatalytic Microparticles by Interfacial Self-Assembly of Enzyme-Nanoparticle Conjugates Around a Cross-Linkable Core, Methods Enzymol., 2016, 571, $1-17$.

172 S. M. Andler, L.-S. Wang, V. M. Rotello and J. M. Goddard, Influence of Hierarchical Interfacial Assembly on Lipase Stability and Performance in Deep Eutectic Solvent, J. Agric. Food Chem., 2017, 65, 1907-1914.

173 A. Della Martina, J. G. Hilborn and A. Mühlebach, Macroporous Cross-Linked Poly(dicyclopentadiene), Macromolecules, 2000, 33, 2916-2921.

174 A. Della Martina and J. G. Hilborn, Gradient porosity poly(dicyclopentadiene), J. Mater. Res., 2001, 16, 2045-2052.
175 A. Della Martina, L. Garamszegi and J. G. Hilborn, Pore size modification of macroporous crosslinked poly(dicyclopentadiene), J. Polym. Sci., Part A: Polym. Chem., 2003, 41, 2036-2046.

176 A. Della Martina, L. Garamszegi and J. G. Hilborn, Surface functionalization of cross-linked poly(dicyclopentadiene), React. Funct. Polym., 2003, 57, 49-55.

177 M. Perring and N. B. Bowden, Assembly of Organic Monolayers on Polydicyclopentadiene, Langmuir, 2008, 24, 10480-10487.

178 M. Perring, T. R. Longa and N. B. Bowden, Epoxidation of the surface of polydicyclopentadiene for the self-assembly of organic monolayers, J. Mater. Chem., 2010, 20, 8679-8685.

179 T. Zhang, R. A. Sanguramath, S. Israel and M. S. Silverstein, Emulsion Templating: Porous Polymers and Beyond, Macromolecules, 2019, 52, 5445-5479.

180 K. Benmachou, H. Deleuze and V. Heroguez, Ring opening polymerisation of highly concentrated inverse emulsions to obtain microcellular foams, React. Funct. Polym., 2003, 55, 211-217.

181 S. Kovačič, P. Krajnc and C. Slugove, Inherently Reactive polyHIPE Material from Dicyclopentadien, Chem. Commun., 2010, 46, 7504-7506.

182 S. Kovačič, K. Jeřabek, P. Krajnc and C. Slugove, Ring Opening Metathesis Polymerisation of emulsion templated dicyclopentadiene giving open porous materials with excellent mechanical properties, Polym. Chem., 2012, 3, 325-328.

183 S. Kovačič, N. B. Matsko, K. Jeřabek, P. Krajnc and C. Slugove, On the Mechanical Properties of HIPE Templated Macroporous poly(Dicyclopentadiene) Prepared with Low Surfactant Amounts, J. Mater. Chem. A, 2013, 1, 487-490.

184 S. Kovačič, E. Žagar and C. Slugovc, Strength versus toughness of emulsion templated poly(dicyclopentadiene) foams, Polymer, 2019, 169, 58-65.

185 S. Kovačič, F. Preishuber-Pflügl and C. Slugove, Macroporous Polyolefin Membranes from Dicyclopentadiene High Internal Phase Emulsions: Preparation and Morphology Tuning, Macromol. Mater. Eng., 2014, 299, 843-850.

186 S. Kovačič, H. Kren, P. Krajnc, S. Koller and C. Slugove, The use of an emulsion templated microcellular poly(dicyclopentadiene-co-norbornene) membrane as separator in lithium-ion batteries, Macromol. Rapid Commun., 2013, 34, 581-587.

187 E. H. Mert, C. Slugovc and P. Krajnc, Tailoring the Mechanical and Thermal Properties of Dicyclopentadiene PolyHIPEs with the Use of a Comonomer, Express Polym. Lett., 2015, 9, 344-353.

188 E. Vakalopoulou and C. Slugovc, The effects of enhancing the crosslinking degree in high internal phase emulsion templated poly(dicyclopentadiene), Macromol. Chem. Phys., 2019, 220, 1900423.

189 S. Kovačič, N. B. Matsko, G. Ferk and C. Slugove, Macroporous poly(dicyclopentadiene) $\gamma \mathrm{Fe}_{2} \mathrm{O}_{3} / \mathrm{Fe}_{3} \mathrm{O}_{4}$ nanocomposite foams by high internal phase emulsion templating, J. Mater. Chem. A, 2013, 1, 7971-7978.

190 S. Kovačič, A. Anžlovar, B. Erjavec, G. Kapun, N. B. Matsko, M. Zigon, E. Zagar, A. Pintar and C. Slugovc, Macroporous ZnO Foams by High Internal Phase Emulsion Technique: 
Synthesis and Catalytic Activity, ACS Appl. Mater. Interfaces, 2014, 6, 19075-19081.

191 E. Yüce, E. H. Mert, P. Krajnc, F. N. Parın, N. San, D. Kaya and H. Yıldırım, Photocatalytic Activity of Titania/Polydicyclopentadiene PolyHIPE Composites, Macromol. Mater. Eng., 2017, 302, 1700091.

192 E. Yüce, P. Krajnc, H. H. Mert and E. H. Mert, Influence of nanoparticles and antioxidants on mechanical properties of titania/polydicyclopentadiene polyHIPEs: A statistical approach, J. Appl. Polym. Sci., 2019, 136, 46913.

193 S. Kovačič, M. Mazaj, M. Jeselnik, D. Pahovnik, E. Žagar, C. Slugove and N. Zabukovec Logar, Synthesis and Catalytic Performance of Hierarchically Porous MIL-100(Fe)@polyHIPE Hybrid Membranes, Macromol. Rapid Commun., 2015, 36, 1605-1611.

194 M. Mazaj, N. Zabukovec Logar, E. Žagar and S. Kovačič, A facile strategy towards a highly accessible and hydrostable MOF-phase within hybrid polyHIPEs through in situ metal-oxide recrystallization, J. Mater. Chem. A, 2017, 5, 1967-1971.

195 S. M. Andler and J. M. Goddard, Stabilization of Lipase in Polymerized High Internal Phase Emulsions, J. Agric. Food Chem., 2018, 66, 3619-3623.

196 N. Trupej, Z. Novak, Ž. Knez, C. Slugove and S. Kovačič, Supercritical $\mathrm{CO}_{2}$ Mediated Functionalization of Highly Porous Emulsion-Derived Foams: $\mathrm{scCO}_{2}$ Absorption and Epoxidation, J. CO2 Util., 2017, 21, 336-341.

197 A.-C. Knall, S. Kovačič, M. Hollauf, D. P. Reishofer, R. Saf and C. Slugovc, Inverse electron demand Diels-Alder (iEDDA) functionalisation of macroporous poly(dicyclopentadiene) foams, Chem. Commun., 2013, 49, 7325-7327.

198 Z. Yao, Z. Wang, Y. Yu, C. Zeng and K. Cao, Facile synthesis and properties of the chemo-reversible and highly tunable metallogels based on polydicyclopentadiene, Polymer, 2017, 119, 98-106.

199 C. L. McGann, G. C. Daniels, S. L. Giles, R. B. Balow, J. L. Miranda-Zayas, J. G. Lundin and J. H. Wynne, Air Activated Self-Decontaminating Polydicyclopentadiene PolyHIPE Foams for Rapid Decontamination of Chemical Warfare Agents, Macromol. Rapid Commun., 2018, 39, 1800194.

200 R. B. Balow, S. L. Giles, C. L. McGann, G. C. Daniels, J. G. Lundin, P. E. Pehrsson and J. H. Wynne, Rapid Decontamination of Chemical Warfare Agent Simulant with Thermally Activated Porous Polymer Foams, Ind. Eng. Chem. Res., 2018, 57, 8630-8634.

201 E. Vakalopoulou, S. M. Borisov and C. Slugovc, Fast oxygen scavenging of macroporous poly(norbornadiene) prepared by Ring-opening Metathesis Polymerization, Macromol. Rapid Commun., 2020, 41, 1900581.

202 S. Kovačič, N. B. Matsko, K. Gruber, S. Koller and C. Slugovc, Ring-Opening Metathesis Polymerization Derived Hierarchically Porous Carbon-Foams, ChemRxiv, 2020, DOI: 10.26434/chemrxiv.11674041.v1.

203 J. K. Lee and G. L. Gould, Polydicyclopentadiene based aerogel: a new insulation material, J. Sol-Gel Sci. Technol., 2007, 44, 29-40.
204 C. Dawedeit, S. H. Kim, T. Braun, M. A. Worsley, A. L. Stephan, K. J. Wu, C. C. Walton, A. A. Chernov, J. H. Satcher Jr., A. V. Hamza and J. Biener, Tuning the rheological properties of sols for low-density aerogel coating applications, Soft Matter, 2012, 8, 3518-3521.

205 S. H. Kim, M. A. Worsley, C. A. Valdez, S. J. Shin, C. Dawedeit, T. Braun, T. F. Baumann, S. A. Letts, S. O. Kucheyev, K. J. J. Wu, J. Biener, J. H. Satcher, Jr. and A. V. Hamza, Exploration of the versatility of ring opening metathesis polymerization: an approach for gaining access to low density polymeric aerogels, RSC Adv., 2012, 2, 8672-8680.

206 S. H. Kim, S. J. Shin, J. M. Lenhardt, T. Braun, J. D. Sain, C. A. Valdez, R. N. Leif, S. O. Kucheyev, K. J. J. Wu, J. Biener, J. H. Satcher, Jr. and A. V. Hamza, Deterministic control over high-Z doping of polydicyclopentadiene-based aerogel coatings, ACS Appl. Mater. Interfaces, 2013, 5, 8111-8119.

207 D. P. Mohite, S. Mahadik-Khanolkar, H. Luo, H. Lu, C. Sotiriou-Leventis and N. Leventis, Polydicyclopentadiene aerogels grafted with PMMA: I. Molecular and interparticle crosslinking, Soft Matter, 2013, 9, 1516-1530.

208 D. P. Mohite, S. Mahadik-Khanolkar, H. Luo, H. Lu, C. Sotiriou-Leventis and N. Leventis, Polydicyclopentadiene aerogels grafted with PMMA: II. Nanoscopic characterization and origin of macroscopic deformation, Soft Matter, 2013, 9, 1531-1539.

209 G. Raptopoulos, G. C. Anyfantis, D. Chriti and P. Paraskevopoulou, Synthesis and structural characterization of poly(dicyclopentadiene) gels obtained with a novel ditungsten versus conventional $\mathrm{W}$ and $\mathrm{Ru}$ mononuclear catalysts, Inorg. Chim. Acta, 2017, 460, 69-76.

210 D. Chriti, G. Raptopoulos, G. C. Anyfantis and P. Paraskevopoulou, An Extreme Case of Swelling of Mostly cis-Polydicyclopentadiene by Selective Solvent AbsorptionApplication in Decontamination and Environmental Remediation, ACS Appl. Polym. Mater., 2019, 1, 1648-1659.

211 D. Chriti, G. Raptopoulos, B. Brandenburg and P. Paraskevopoulou, Large, Rapid Swelling of High-cis Polydicyclopentadiene Aerogels Suitable for Solvent-Responsive Actuators, Polymers, 2020, 12, 1033.

212 J. M. Lenhardt, S. H. Kim, A. J. Nelson, P. Singhal, T. F. Baumann and J. H. Satcher Jr, Increasing the oxidative stability of poly(dicyclopentadiene) aerogels by hydrogenation, Polymer, 2013, 54, 542-547.

213 T. R. Long, A. Gupta, A. L. Miller, D. G. Rethwisch and N. B. Bowden, Selective flux of organic liquids and solids using nanoporous membranes of polydicyclopentadiene, J. Mater. Chem., 2011, 21, 14265-14276.

214 A. Gupta, T. R. Long, D. G. Rethwisch and N. B. Bowden, Retention of palladium and phosphine ligands using nanoporous polydicyclopentadiene thimbles, Chem. Commun., 2011, 47, 10236-10238.

215 A. Gupta and N. B. Bowden, Separation of cis-fatty acids from saturated and trans-fatty acids by nanoporous polydicyclopentadiene membranes, ACS Appl. Mater. Interfaces, 2013, 5, 924-933. 
216 L. Chen, W. A. Phillip, E. L. Cussler and M. A. Hillmyer, Robust Nanoporous Membranes Templated by a Doubly Reactive Block Copolymer, J. Am. Chem. Soc., 2007, 129, 13786-13787.

217 M. A. Amendt, L. Chen and M. A. Hillmyer, Formation of Nanostructured Poly(dicyclopentadiene) Thermosets Using Reactive Block Polymers, Macromolecules, 2010, 43, 3924-3934.

218 W. A. Phillip, M. Amendt, B. O'Neill, L. Chen, M. A. Hillmyer and E. L. Cussler, Diffusion and Flow Across Nanoporous Polydicyclopentadiene-Based Membranes, ACS Appl. Mater. Interfaces, 2009, 1, 472-480.

219 L. Chen and M. A. Hillmyer, Mechanically and Thermally Robust Ordered Nanoporous Monoliths Using NorborneneFunctional Block Polymers, Macromolecules, 2009, 42, 4237-4243.

220 M. A. Amendt, M. Roerdink, S. Moench, W. A. Phillip, E. L. Cussler and M. A. Hillmyer, Functionalized Nanoporous Membranes from Reactive Triblock Polymers, Aust. J. Chem., 2011, 64, 1074-1082.

221 T. J. Clark, N. J. Robertson, H. A. Kostalik IV, E. B. Lobkovsky, P. F. Mutolo, H. D. Abruna and G. W. Coates, A ring-opening metathesis polymerization route to alkaline anion exchange membranes: development of hydroxide-conducting thin films from an ammonium-functionalized monomer, J. Am. Chem. Soc., 2009, 131, 12888-12889.

222 S. C. Price, X. M. Ren, A. C. Jackson, Y. S. Ye, Y. A. Elabdand and F. L. Beyer, Bicontinuous Alkaline Fuel Cell Membranes from Strongly Self-Segregating Block Copolymers, Macromolecules, 2013, 46, 7332-7340.

223 X. Ren, S. C. Price, A. C. Jackson, N. Pomerantz and F. L. Beyer, Highly Conductive Anion Exchange Membrane for High Power Density Fuel-Cell Performance, ACS Appl. Mater. Interfaces, 2014, 6, 13330-13333.

224 Y. Zha, M. L. Disabb-Miller, Z. D. Johnson, M. A. Hickner and G. N. Tew, Metal-Cation-Based Anion Exchange Membranes, J. Am. Chem. Soc., 2012, 134, 4493-4496.

225 M. L. Disabb-Miller, Y. Zha, A. J. DeCarlo, M. Pawar, G. N. Tew and M. A. Hickner, Water Uptake and Ion Mobility in Cross-Linked Bis(terpyridine)ruthenium-Based Anion Exchange Membranes, Macromolecules, 2013, 46, 9279-9287.

226 M. T. Kwasny and G. N. Tew, Expanding metal cation options in polymeric anion exchange membranes, J. Mater. Chem. A, 2017, 5, 1400-1405.

227 M. T. Kwasny, L. Zhu, M. A. Hickner and G. N. Tew, Thermodynamics of Counterion Release Is Critical for Anion Exchange Membrane Conductivity, J. Am. Chem. Soc., 2018, 140, 7961-7969.

228 L. Chen, D. T. Hallinan, Jr., Y. A. Elabd and M. A. Hillmyer, Highly Selective Polymer Electrolyte Membranes from Reactive Block Polymers, Macromolecules, 2009, 42, 6075-6085.

229 W. A. Phillip, E. Martono, L. Chen, M. A. Hillmyer and E. L. Cussler, Seeking an ammonia selective membrane based on nanostructured sulfonated block copolymers, J. Membr. Sci., 2009, 337, 39-46.

230 X. Li, Y. Zhao, Z. Feng, X. Xiang, S. Wang, X. Xie and V. K. Ramani, Ring-opening metathesis polymerization for the preparation of polynorbornene-based proton exchange membranes with high proton conductivity, J. Membr. Sci., 2017, 528, 55-63.

231 C. Wang, Z. Feng, Y. Zhao, X. Li, W. Li, X. Xie, S. Wang and H. Hou, Preparation and properties of ion exchange membranes for PEMFC with sulfonic and carboxylic acid groups based on polynorbornenes, Int. J. Hydrogen Energy, 2017, 42, 29988-29994.

232 T. J. Cuthbert, J. Chen, F. P. Burns, M. G. Moffitt and J. E. Wulff, Thermally Crosslinked Functionalized Polydicyclopentadiene with a High $\mathrm{T}_{\mathrm{g}}$ and Tunable Surface Energy, ACS Omega, 2016, 1, 532-540.

233 T. J. Cuthbert, T. Li, A. W. H. Speed and J. E. Wulff, Structure of the Thermally Induced Cross-Link in C-Linked Methyl Ester-Functionalized Polydicyclopentadiene (fPDCPD), Macromolecules, 2018, 51, 2038-2047.

234 T. J. Cuthbert, T. Li and J. E. Wulff, Production and Dynamic Mechanical Analysis of Macro-Scale Functionalized Polydicyclopentadiene Objects Facilitated by Rational Synthesis and Reaction Injection Molding, ACS Appl. Polym. Mater., 2019, 1, 2460-2471.

235 L. Gong, K. Liu, E. Ou, F. Xu, Y. Lu, Z. Wang, T. Gao, Z. Yang and W. Xu, ROMP of acetoxy-substituted dicyclopentadiene to a linear polymer with a high $\mathrm{T}_{\mathrm{g}}, R S C A d v$., 2015, 5, 26185-26188.

236 S. Saha, Y. Ginzburg, I. Rozenberg, O. Iliashevsky, A. BenAsuly and N. G. Lemcoff, Cross-linked ROMP polymers based on odourless dicyclopentadiene derivatives, Polym. Chem., 2016, 7, 3071-3075.

237 R. S. Phatake, A. Masarwa, N. G. Lemcoff and O. Reany, Tuning thermal properties of cross-linked DCPD polymers by functionalization, initiator type and curing methods, Polym. Chem., 2020, 11, 1742-1751.

238 J. E. Amoore and E. Hautala, Odor as an aid to chemical safety: Odor thresholds compared with threshold limit values and volatilities for 214 industrial chemicals in air and water dilution, J. Appl. Toxicol., 1983, 3, 272-290.

239 L. G. Stehmeier, M. M. Francis, T. R. Jack and G. Voordouw, Biodegradation of Dicyclopentadiene in the Field, Biodegradation, 1999, 10, 135-148.

240 K. M. Kransler, Results of a 90-day inhalation study of dicyclopentadiene in B6C3F1 mice, Toxicol. Ind. Health, 2014, 30, 459-466.

241 P. Shieh, W. Zhang, K. E. L. Husted, S. L. Kristufek, B. Xiong, D. J. Lundberg, J. Lem, D. Veysset, Y. Sun, K. A. Nelson, D. L. Plata and J. A. Johnson, A Comonomer Strategy for Triggered Degradation and Re/Upcycling of High-Performance Thermoset Plastics, ChemRxiv, 2019, DOI: 10.26434/chemrxiv.11328242.v1. 